\title{
CINE, PROPAGANDA Y EL MUNDO DE DISNEY EN CHILE DURANTE LA SEGUNDA GUERRA MUNDIAL ${ }^{* *}$
}

\begin{abstract}
RESUMEN
El artículo estudia el fenómeno e impacto de la propaganda cinematográfica de Estados Unidos en Chile durante la Segunda Guerra Mundial. Se argumenta que la serie de proyectos fílmicos planeados y realizados por Estados Unidos durante el conflicto fueron parte de una diplomacia cultural que no estuvo escindida de los principales lineamientos diplomáticos trazados desde Washington. Por el contrario, queda de manifiesto la estrecha vinculación de la industria hollywoodense con el Departamento de Estado. El cine y otras formas de propaganda tuvieron una amplia difusión en el país, y contribuyeron a consolidar el mensaje de Estados Unidos entre la población chilena, independiente de reacciones negativas puntuales, asociadas a representaciones cinematográficas de Chile que hirieron sensibilidades identitarias de parte de la ciudadanía.
\end{abstract}

Palabras clave: cine, propaganda, diplomacia cultural, Segunda Guerra Mundial, Hollywood, Disney, identidad, Estados Unidos, Chile.

\begin{abstract}
This article studies the phenomena and the impact of propaganda film from the United States in Chile during the World War II. I argue that the series of film projects planned and created by the United States during the conflict were part of a cultural diplomacy that was not separated from Washington's main diplomatic guidelines. On the contrary the close connection between the Hollywood film industry and the Department of State is evident. Independent of specific negative reactions associated with representations that hurt Chilean identity, film and other forms of propaganda were largely circulated throughout the country and contributed to the consolidation of the United State's message within the Chilean population.
\end{abstract}

Key words: film, propaganda, cultural diplomacy, World War II, Hollywood, Disney, identity, United States, Chile.

Fecha de recepción: mayo de 2010

Fecha de aceptación: octubre de 2010

* Doctor en Historia de los Estados Unidos, University of California, Davis. Profesor del Instituto de Historia de la Pontificia Universidad Católica de Chile. Correo electrónico: fpurcell@uc.cl

** Este artículo es resultado de una investigación financiada por el proyecto Fondecyt Regular de Iniciación $\mathrm{N}^{\mathrm{o}} 11060303$. 
Juan Pérez y María Pérez casi alcanzaron el estrellato hollywoodense en plena Segunda Guerra Mundial. Eran los nombres de los personajes principales de Chile: una nación valiente, un filme sobre el país en el que se trabajó durante meses, aunque nunca fue rodado; como testimonio del proyecto quedaron el guión y sus borradores, además de cartas relacionadas con la producción y los documentos que inspiraron a John C. Higgins, su guionista ${ }^{1}$. La película había sido encargada por la Motion Picture Society for the Americas (en adelante MPSA), una sociedad instrumental creada en marzo de 1941 por los distintos estudios de Hollywood y apoyada por el Departamento de Estado, con la finalidad de promover las buenas relaciones entre Estados Unidos y América Latina durante la Segunda Guerra Mundial ${ }^{2}$. La organización había sido establecida a instancias de una repartición pública conocida como Office of the Coordinator of Inter American Affairs (en adelante OCIAA), organismo dirigido por Nelson Rockefeller, que funcionaba bajo la tutela del Departamento de Estado. ¿Qué motivó a los estudios de Hollywood a intentar darle protagonismo cinematográfico a Juan y María Pérez en Chile: una nación valiente? La respuesta está en las palabras de Walter Wanger, presidente de la MPSA, quien en un reporte de 1942 precisó que "la película busca cambiar la neutralidad de Chile por una declaración de guerra contra el Eje"3. No sería la última vez que Estados Unidos recurriría al séptimo arte con ese tipo de finalidades, por cuanto en mayo de 1943 Joseph E. Davies, quien fuera embajador de Estados Unidos en la Unión Soviética entre 1936 y 1938, fue enviado a Moscú con la misión de convencer al propio Joseph Stalin (un fanático del cine hollywoodense) de que no negociase la paz con Adolf Hitler en forma individual, buscando que se mantuviera cercano al bloque de Estados Unidos, Francia y Gran Bretaña. Davies no iba provisto de documentos escritos, sino de un maletín con la película Mission to Moscow, que buscaba contribuir además al acercamiento del pueblo soviético a Estados Unidos, promoviendo una visión idealizada del estilo de vida de los norteamericanos ${ }^{4}$.

1 Toda la documentación relativa al proyecto se encuentra disponible en la Margaret Herrick Library, Beverly Hills, California (en adelante MHL). El guionista, John C. Higgins, utilizó una serie de documentos para escribir el guión, entre los que se cuentan boletines de la Unión Panamericana y del Office of the Coordinator of Inter American Affairs, además del libro A History of Chile de Luis Galdames. MHL, Motion Picture Society for the Americas Records, Caja 4, Carpeta "Chile"; Caja 8, Carpeta "Chile: Valiant Nation"; y Caja 9, Carpeta "CHILE by John C. Higgins".

2 El directorio de la organización estaba compuesto por representantes de los estudios de Hollywood y en abril de 1941 se estableció un acuerdo de cooperación entre la OCIAA y la MPSA. La copia del documento notarial que le dio origen a la organización está en National Archives II, College Park, Estados Unidos (en adelante NARA), Record Group (en adelante RG) 229, Caja 952, Carpeta "Liason Office With Motion Picture Industry".

3 Reporte mensual de la Motion Picture Society for the Americas, noviembre de 1942. NARA, RG 229, Caja 961, Carpeta "Monthly Reports", 15. Todas las traducciones de la documentación citada han sido realizadas por el autor. Cabe recordar que Chile rompería relaciones con el Eje recién en enero de 1943, lo que explica esta obsesión diplomática de Estados Unidos, que fuera canalizada también a través de la propaganda fílmica.

4 Todd Bennett, "Culture, Power, and Mission to Moscow: Film and Soviet-American Relations during World War II", en Journal of American History 88:2, Bloomington, septiembre de 2001, 489518 . 
Este tipo de proyectos cinematográficos de la Segunda Guerra Mundial y su intencionalidad han sido poco explorados para el caso de las relaciones internacionales entre Chile y Estados Unidos ${ }^{5}$, por lo que este artículo se propone relevarlos, demostrando que existió una estrecha vinculación entre industrias culturales como la del cine y fines diplomáticos trazados desde las más altas esferas gubernamentales de Estados Unidos. Sin embargo, se argumenta lo anterior siguiendo los postulados de Akira Iriye, en el sentido de que "en el estudio de las relaciones internacionales, cultura puede ser definida como comunicación y una aproximación cultural, como una perspectiva que presta especial atención a la comunicación dentro y entre naciones"6. Se destaca esto porque no es posible pensar en la diplomacia cultural disociada de la diplomacia con mayúscula. Por el contrario, la diplomacia cultural es parte constitutiva de los canales diplomáticos regulares, aunque cambien sus formas producto del énfasis comunicativo, normalmente vinculado a una cultura de masas $^{7}$. Lo que resulta novedoso de este trabajo no es entonces el reconocimiento del uso de herramientas culturales para efectos diplomáticos por parte de Estados Unidos durante la Segunda Guerra Mundial, sino la forma en que devela el grado de compenetración y vinculación entre el Departamento de Estado y Hollywood.

Este tema brinda nuevos espacios historiográficos para el análisis de la praxis de la diplomacia cultural y el estudio de sus efectos y posibilidades en un escenario como el de Chile durante el gran conflicto bélico de mediados del siglo $\mathrm{XX}^{8}$, lo

5 En relación a trabajos recientes sobre las relaciones diplomáticas chilenas durante la Segunda Guerra Mundial, véase José del Pozo, "Las relaciones entre Chile y Canadá durante la Segunda Guerra Mundial. Las primeras experiencias de los diplomáticos chilenos", en Historia 38:I, Santiago, junio de 2005, 31-42; y Raffaele Nocera, "Ruptura con el Eje y alineamiento con Estados Unidos. Chile durante la Segunda Guerra Mundial", en Historia 38:II, Santiago, diciembre de 2005, 397-444. De años anteriores destaca el trabajo de M. Barros van Buren, La Diplomacia chilena en la Segunda Guerra Mundial, Santiago, Universidad de Chile, 1998; y el de M. J. Francis, The Limits of Hegemony: United States Relations with Argentina and Chile during World War II, South Bend, University of Notre Dame Press, 1977. También está el artículo de Joaquín Fermandois "Guerra y hegemonía. Un aspecto de las relaciones chileno-norteamericanas", en Historia 23, Santiago, 1988, 5-51, junto a otros trabajos suyos acerca de la diplomacia y las relaciones económicas previas al conflicto, como "Del unilateralismo a la negociación. Chile, Estados Unidos y la deuda de largo plazo 1934-1938", en Historia 26, Santiago, 1991, 71-115; y su libro Abismo y cimiento: Gustavo Ross y las relaciones entre Chile y Estados Unidos, 1932-1938, Santiago, Ediciones Universidad Católica de Chile, 1997.

6 Akira Iriye, "Culture", en Journal of American History 77:1, Bloomington, junio de 1990, 99.

7 Con respecto al desarrollo de una cultura de masas en Chile, véase Stefan Rinke, Cultura de masas: reforma y nacionalismo en Chile 1910-1931, Santiago, Centro de Investigaciones Barros Arana, Universidad Católica de Valparaíso y Katholische Universitat Eichstatt, 2002; y Carlos Ossandón y Eduardo Santa Cruz, El estallido de las formas. Chile en los albores de la "cultura de masas", Santiago, Lom Ediciones-ARCIS, 2005.

8 Si bien es cierto que queda mucho camino por recorrer para el caso de Chile, este es un tema que se viene desarrollando con fuerza desde la década de 1980, para el análisis de las relaciones diplomáticas de Estados Unidos con Europa, y más recientemente de dicho país con América Latina. Véase por ejemplo, Michael J. Hogan y Thomas G. Paterson, Explaining the History of American Foreign Relations, Cambridge, Cambridge University Press, 1991; Frank Costigliola, Akward Dominion: American Political, Economic, and Cultural Relations with Europe, 1919-1933, Ithaca, Cornell University Press, 1984; Frank A. Ninkovich, The Diplomacy of Ideas: U.S. Foreign Policy and Cultural Relations, 1938-1950, Cambridge, Cambridge University Press, 1981; Emily S. Rosenberg, Spreading the American dream: American Economic and Cultural Expansion, 1890-1945, New York, Hill 
que obliga a incorporar, para el estudio de las relaciones internacionales entre ambos países, a diversos actores, tanto estatales como no estatales, que van desde Nelson Rockefeller y Walt Disney, hasta olvidados y desconocidos protagonistas chilenos como Mario Cisternas, Sergio Tondreau o Eulogio Velasco, quienes trabajaron proyectando películas de propaganda de Estados Unidos en diversas ciudades y poblados del país a inicios de la década de $1940^{9}$.

\section{DEL CINE COMERCIAL AL CINE COMO HERRAMIENTA DIPLOMÁTICA}

En la sección editorial del primer número de la revista chilena Hollywood, aparecida en 1926, ya se reflexionaba acerca del impacto del cine en el mundo, al destacar que

"[es] un hecho probado que el cinematógrafo ejerce hoy una influencia enorme sobre los pueblos. Alcanzando esta influencia a más individuos y de manera más efectiva que la prensa, podemos con fundamento pensar que el cine constituirá, en un futuro no lejano, un quinto poder, tan poderoso o más que el cuarto".

En un tono más particular, agregaba que las películas norteamericanas se habían constituido en "los más importantes medios de propaganda de los ideales y costumbres de ese país, y aun de los innumerables artículos que los Estados Unidos producen", añadiendo el comentario de que "cada película, por insignificante que sea, lleva la misión inconsciente de dar a conocer las costumbres o ideales del pueblo donde se hace e incidentalmente ayuda a crear la demanda por todo cuanto en ella aparece"10. De esto último había plena conciencia en Estados Unidos, al punto de que ese mismo año el presidente Calvin Coolidge reconocía públicamente que la industria cinematográfica ocupaba un lugar privilegiado dentro de las exportaciones de su país, opinando que esta debía "ser impulsada por el gobierno empleando cualquier medio legítimo"11.

En 1928 los publicistas estadounidenses declaraban que la exhibición de filmes en el extranjero generaba "una avalancha de órdenes de compra" y que las películas funcionaban como "suplementos" o "agentes de venta" fuera del país. Frederick L. Herron de la Motion Picture Producers and Distributors of America, el principal organismo articulador de los intereses de los grandes estudios de Hollywood, establecido en 1922, declaraba que la exhibición de películas potenciaba la venta de productos como tinas, máquinas de coser, automóviles y cientos de mercancías,

and Wang, 1982; Walter L. Hixon, Parting the Curtain: Propaganda, Culture, and the Cold War, 1945-1961, New York, Saint Martin’s Press, 1997. Para el caso de las relaciones entre Estados Unidos y América Latina, destaca el trabajo de Gilbert Joseph, Ricardo Salvatore y Catherin Legrand (editores), Close Encounters of Empire: Writing the Cultural History of U.S.-Latin American Relations, Durham, Duke University Press, 1998.

9 Motion Pictures Budget Request, 13 de junio de 1945. NARA, RG 229, Caja 954, Carpeta "Coordination Committee Motion Picture Activities, Chile".

10 Hollywood, Santiago, número 1, noviembre de 1926.

11 The Washington Post, Washington, 21 de abril de 1926. 
con lo que quedaba en evidencia que los filmes "generan un deseo por artículos manufacturados de Estados Unidos y allanan el camino de los vendedores"12. Debido al éxito comercial, derivado de la enorme influencia social y cultural que ejercía el cine, las autoridades gubernamentales norteamericanas comenzaron paulatinamente a evaluar las posibilidades del uso del séptimo arte como una herramienta que trascendiera la esfera comercial y se incorporase de lleno al ámbito de las políticas públicas y campañas gubernamentales, lo que sentó las bases para su posterior utilización en el ámbito de la diplomacia cultural durante la Segunda Guerra Mundial y la Guerra Fría.

En medio de una compleja situación económica y bajo la imperiosa necesidad de abrir mercados internacionales para superar la grave crisis económica iniciada en Estados Unidos en 1929, el presidente Franklin Delano Roosevelt terminó de delinear un nuevo proyecto de relaciones diplomáticas con América Latina. Es así como Estados Unidos transitó en las primeras décadas del siglo veinte desde la denominada política del gran garrote, caracterizada por el intervencionismo contra aquellos países "injustos" y "desordenados", a la formulación de la política del buen vecino en 1933, que buscó fortalecer los lazos de Estados Unidos con Latinoamérica $^{13}$. La nueva política se puede explicar por diversas razones, entre ellas la configuración de un nuevo escenario tras la crisis económica de 1929, que fortaleció el nacionalismo económico en muchos rincones de América Latina, y un nuevo protagonismo de masas urbanas, con demandas más radicales que amenazaban con poner en jaque los intereses norteamericanos en la zona. En ese sentido, Estados Unidos buscaba evitar la restricción de sus posibilidades de comercio en la región, además de mantener su peso diplomático en la zona, todo lo cual se había venido construyendo con el impulso al desarrollo de proyectos panamericanos ${ }^{14}$. A lo anterior hay que agregar las turbulencias europeas y la eventualidad de un nuevo conflicto a gran escala, realidades que llevaron al país del norte a plantear la necesidad del fortalecimiento de los vínculos y cooperación interamericana, como una forma de constitución de un bloque hemisférico más sólido del que existía ${ }^{15}$.

12 Christian Science Monitor, Boston, 21 de marzo de 1928. Respecto al tema de la vinculación entre cine y consumo, véase Fernando Purcell, "Una mercancía irresistible. El cine norteamericano y su impacto en Chile, 1910-1930", en Historia Crítica 38, Bogotá, 2009, 46-69; Victoria de Grazia, Irresistible Empire. America's Advance through 20th-Century Europe, Cambridge, Harvard University Press, 2005; y Kristin Thompson, Exporting Entertainment. America in the World Film Market 19071934, Londres, BFI, 1985.

13 La política del gran garrote derivó de la reinterpretación de la doctrina Monroe, originalmente formulada por James Monroe en 1823. En su mensaje anual al Congreso del 6 de diciembre de 1904, el presidente Theodore Roosevelt formuló el denominado Corolario de la Doctrina Monroe, donde hizo explícita su posición de respaldar el derecho a intervención y uso de la fuerza de un Estado contra otro para recolectar deudas impagas o zanjar el incumplimiento de acuerdos de diversa índole. Robert H. Holden y Eric Zolov (editores), Latin America and the United States. A Documentary History, Nueva York, Oxford University Press, 2000, 100-102.

14 Ricardo Salvatore, "Panamericanismo práctico. Acerca de la mecánica de la penetración comercial norteamericana", en Ricardo Salvatore (compilador), Culturas imperiales. Experiencia y representación en América, Asia y África, Rosario, Beatriz Viterbo Editora, 269-300.

15 Raffaele Nocera, Chile y la guerra 1933-1943, Santiago, Centro de Investigaciones Barros Arana, 2006. 
Si bien es cierto la política del buen vecino tuvo un claro trasfondo económico y político, no puede ser entendida simplemente como un esfuerzo diplomático en el que participaron agencias gubernamentales, sino como un proyecto en el que también se dieron cita representantes del mundo de los negocios, medios e industrias culturales, como las de la radio y el cine ${ }^{16}$. El cine tuvo un lugar protagónico como medio educativo, informativo y propagandístico, producto de que la política del buen vecino coincidió con un período histórico en el que los numerosos proyectos y reformas de gobierno fueron apoyados con este tipo de medios. Por ejemplo, durante los años de la Gran Depresión, el gobierno de Estados Unidos destinó una cantidad importante de recursos a la realización de películas que, con motivos visuales dramáticos, música y narraciones poéticas, dieron cuenta de problemas como los del medio ambiente, que afectaron vastas zonas del oeste del país a propósito del fenómeno del Dust Bowl ${ }^{17}$. En la década de 1930 hubo 20 agencias gubernamentales que produjeron filmes y solo el Departamento de Agricultura financió más de 200 películas documentales y educacionales ${ }^{18}$. La proyección en el tiempo de este tipo de iniciativas fue evidente, puesto que muchos de los directores que se hicieron cargo de estos filmes tendrían un rol preponderante en el transcurso de la Segunda Guerra Mundial, preparando películas de instrucción militar, de concientización ideológica y propaganda, que fueron dirigidas tanto a la sociedad de Estados Unidos como al mundo.

No transcurrieron muchos años hasta que el cine se convirtió en una herramienta diplomática. Fue la propia industria fílmica, a instancias del Departamento de Estado, la que una vez formulada la política del buen vecino se comprometió a revisar cada guión antes de que entrara a la etapa final de producción, de modo de evitar representaciones que ofendieran a América Latina. Vivo estaba el recuerdo de películas que habían generado la censura de los filmes hollywoodenses en México en 1922, 1924 y 1927, por la representación negativa de los caracteres mexicanos que se hacía en varias de ellas ${ }^{19}$. Esto se canalizó a través de la Production Code Administration, establecida en 1934. Addison Durland, nacido en Cuba, estuvo a cargo de monitorear todo el material que pudiese "ofender" a Latinoamérica desde 1934 en adelante, trabajo evaluado positivamente, al punto de que años más tarde se convirtió en el principal encargado de prohibir cualquier caracteriza-

16 Pennee Bender, Film as an Instrument of the Good Neighbor Policy, 1930s-1950s, Tesis doctoral, Departamento de Historia, New York University, Nueva York, 2002, 6. Véase también, Fred Fejes, Imperialism, Media and the Good Neighbor: New Deal Foreign Policy and United States Shortwave Broadcasting to Latin America, Norwood, Ablex Pub. Corp., 1986, 27-37.

17 Este fue uno de los peores desastres ecológicos de Estados Unidos en el siglo XX. Miles de hectáreas de tierra cultivable fueron dañadas por el efecto de sequías. Producto del mal manejo de los suelos agrícolas, sumado a la sequía, el efecto de la erosión fue fatídico, lo que generó grandes nubes de polvo provenientes de tierras fértiles que fueron desplazadas hacia zonas oceánicas. Cientos de miles de agricultores y campesinos abandonaron sus tierras del medio oeste para trasladarse a otras zonas del país, especialmente California. Donald Worster, Dust Bowl. The Southern Plains in the 1930s, Nueva York, Oxford University Press, 1979.

18 Bender, op. cit., 200.

19 Kerry Segrave, American Films Abroad. Hollywood's Domination of the World's Movie Screens from the 1890s to the Present, Jefferson, McFarland \& Company Publishers,1997, 56. 
ción negativa de América Latina, una vez establecida la división fílmica de la OCIAA, institución creada en 1940, en plena Segunda Guerra Mundial.

Fue durante este grave conflicto mundial cuando la política del buen vecino cobró una importancia estratégica mayor. Por ello el gobierno de Estados Unidos nombró a Nelson Rockefeller a cargo de la OCIAA, procurando que dicho organismo se encargase de articular una política de acercamiento cultural a nivel continental, lo que tenía un claro propósito estratégico. Esta repartición tuvo una serie de ámbitos de desarrollo, pero el cine ocupó un lugar privilegiado, lo que explica la creación de un departamento especializado en el tema: la división fílmica de la OCIAA se preocupó de censurar todo material ofensivo para Latinoamérica, evitar la distribución de películas que dieran una visión errada de la sociedad de Estados Unidos, promover la solidaridad hemisférica, producir cortometrajes que facilitaran el entendimiento interamericano y estimular la presencia de temáticas y música latinoamericana en las producciones hollywoodenses ${ }^{20}$.

John Hay Whitney, quien había sido productor ejecutivo de la película Lo que el viento se llevó, fue el primer encargado de la división fílmica de la OCIAA, puesto que ocupó hasta 1942, cuando pasó al área de inteligencia en la Fuerza Aérea, siendo reemplazado en junio de 1942 por Francis Alstock. Whitney se embarcó en un proyecto que buscaba esparcir los mensajes de libertad y democracia a todos los países latinoamericanos, el cual tenía un claro tenor propagandístico que no fue dirigido al público latinoamericano solamente, sino también al estadounidense. Si la propaganda funcionó en ambos sentidos, es porque para el gobierno de Estados Unidos era tan importante influir en América Latina, como concitar un apoyo interno para el mantenimiento y profundización de la política del buen vecino durante la Segunda Guerra Mundial. El desafío era mostrar películas sobre Estados Unidos y su gente a los habitantes de las otras repúblicas americanas, así como exhibir filmes de las actividades y experiencias de vida latinoamericanas en Estados Unidos. Este último punto era sensible, debido al predominio de ideas negativas sobre la región en el país del norte. El mejor ejemplo es el de una encuesta realizada en 1940, donde se pidió a ciudadanos estadounidenses escoger un número ilimitado de características de los habitantes de América Latina mencionadas espontáneamente, lo que explica que los porcentajes sumados, superaran el $100 \%$. Solo un $5 \%$ de los encuestados consideró que los latinoamericanos eran "eficientes" y un $13 \%$ que eran "honestos". Si bien es cierto las cifras se elevaban para considerarlos "imaginativos", alcanzando un $23 \%$, lo que prevaleció entre el $80 \%$ de los consultados fue su característica racial: "de piel oscura". A esto se agrega el hecho de que un $41 \%$ de las personas consultadas los consideraba "flojos" y un $47 \%$ "emocionales" 21 . No es de extrañar entonces que la OCIAA intentara concentrar parte importante de sus esfuerzos en transformar las nociones que la sociedad estadounidense tenía sobre Latinoamérica, utilizando el cine como herramienta privilegiada para aquello. Sin

20 Bender, op. cit., 112-113.

21 Citado en ibid., 199. 
embargo, los principales esfuerzos estuvieron direccionados a promover una imagen favorable de Estados Unidos en la región.

Además de influir en 150 películas comerciales, ya sea financiando, produciendo, promoviendo la utilización de determinadas locaciones, cambiando guiones o añadiendo secuencias ${ }^{22}$, la OCIAA gestionó la realización de 466 documentales y filmes educacionales entre 1940 y 1945, de modo de acercar mutuamente al público de Estados Unidos y de Latinoamérica. Esto denota un gran esfuerzo diplomático, sin que implique que la industria cultural cinematográfica desarrollase una diplomacia distinta o apartada de las directrices estatales. Muy por el contrario, lo notable fue la sinergia y el nivel de complementariedad que alcanzaron Hollywood y el Departamento de Estado, algo que no hubiese sido posible sin la creación de la OCIAA y sin el destacado papel cumplido por Nelson Rockefeller como articulador de las demandas del gobierno a Hollywood.

Cabe destacar que, a pesar de que existía la intención de dar a conocer Latinoamérica a Estados Unidos, no se contempló la exhibición en este país de cintas producidas en la región. La producción de películas fue esencialmente unidireccional y se concentró en los estudios de Hollywood. Esto reflejaba la actitud propia de un imperio informal que mantuvo el control de la representación cinematográfica de la alteridad latinoamericana ${ }^{23}$. Solo dos películas de América Latina contaron con el beneplácito de la OCIAA para ser exhibidas en Estados Unidos durante la Segunda Guerra Mundial: una mexicana, que promovía el turismo en ese país, y una ecuatoriana, que hacía un llamado a inversores de Estados Unidos para que desarrollaran proyectos en su país ${ }^{24}$. Ni siquiera se apoyaron iniciativas de exhibición de cintas latinoamericanas en otros países de la región, a pesar de intentos como el del chileno Miguel Ávila, director del Instituto de Cinematografía Educativa, quien hizo la solicitud respectiva a Charles Marshall de la Asociación Norteamericana de Cooperación en Chile (en adelante ANCC). La intención de Ávila era desarrollar una cooperación mutua para la exhibición, tanto de películas de la OCIAA como de las realizadas por el Instituto que dirigía, aprovechando los equipos y el despliegue de los organismos de Estados Unidos durante la Segunda Guerra Mundial. La solicitud de Ávila no fue acogida porque, tal como le escribió Charles Marshall,

\footnotetext{
"por razón de los reglamentos generales según los cuales estamos obligados a mantener un control relativamente estricto, no estamos autorizados para dar exhibiciones de películas que no estén aprobadas por el Coordinador de Asuntos Interamericanos y el Departamento de Estado y que no sean suministradas por dichas agencias u otras del gobierno de Estados Unidos"25.
}

22 Ibid., 272-281.

23 Ricardo Salvatore, Imágenes de un imperio. Estados Unidos y las formas de representación de América Latina, Buenos Aires, Editorial Sudamericana, 2006, 12-13.

24 Bender, op. cit., 211.

25 Carta de Charles Marshall a Miguel R. Ávila, Santiago, 21 de enero de 1944. NARA, RG 229, Caja 229, Carpeta "Film-Distribution". 
Todo esto demuestra el estricto control que mantuvo Estados Unidos en la producción de representaciones sobre América Latina, las que debían ser proyectadas a las audiencias locales, sin que se desvirtuaran los fines diplomáticos y propagandísticos que le daban sentido y coherencia a la inmensa cantidad de exhibiciones por ellos controladas.

\section{EXHIBICIÓN DE PELÍCULAS EN CHILE}

El cine hollywoodense ya dominaba las pantallas chilenas al momento del estallido de la Segunda Guerra Mundial. De acuerdo a las estadísticas de películas contenidas en el Boletín Cinematográfico de Chile, en 1935 hubo un total de 279 estrenos en las salas nacionales, de los cuales 204, es decir un $73,1 \%$, fueron producidos en Hollywood. Por su parte, en 1940 hubo 444 estrenos, de los cuales 301 , equivalentes a un $67,7 \%$ del total, correspondieron a películas realizadas en Estados Unidos ${ }^{26}$. Aunque por esos años las producciones latinoamericanas alcanzaban su peak de popularidad, apenas sobrepasaban el $10 \%$ del total de los estrenos en el país. Las cifras son abismantes y demuestran un claro predominio de las cintas hollywoodenses en las pantallas chilenas, lo que ciertamente facilitó la penetración de los cientos de filmes propagandísticos que fueron presentados en Chile durante la Segunda Guerra Mundial.

De acuerdo a un reporte preparado por Archibald Grey, del consulado de Estados Unidos en Santiago, existían 271 salas de cine en Chile en 1942, las que contaban con una capacidad promedio de entre 400 y 500 butacas $^{27}$. La mayoría de las salas se ubicaba en las grandes ciudades, producto de que la expansión del cine estuvo directamente asociada al proceso de conformación de una cultura de masas esencialmente urbana ${ }^{28}$. Sin embargo, el interés de las autoridades de Estados Unidos era que los cientos de filmes educacionales y documentales de propaganda preparados por la OCIAA y la MPSA alcanzaran públicos variados y numerosos. De hecho, si bien fueron ámbitos urbanos los que concentraron los primeros esfuerzos propagandísticos en Chile, el interés por abarcar al público de zonas rurales se hizo realidad a lo largo de la guerra. Detrás de esta decisión estaba el convencimiento de que el cine no solo podía influir en términos de potenciar la empatía de la población rural con el pueblo norteamericano, sino que también podía ayudar a modernizar su vida cotidiana, a través de información que explícitamente se refería a temas relacionados con la salud, la higiene y valores progresistas

26 Las cifras anteriores derivan de una recopilación de información disgregada, contenida en los volúmenes del Boletín Cinematográfico de Santiago, entre 1935 y 1940. Fueron obtenidas a partir de las estadísticas elaboradas por Camila Gatica Mizala para este proyecto de investigación.

27 Reporte "Motion Pictures in Chile", preparado por Archibald Grey, Segundo Secretario, Consulado de Estados Unidos en Santiago, 26 de agosto de 1942. NARA, RG 229, Caja 229, Carpeta "Reports".

28 Rinke, op. cit. 
vinculados a los ámbitos económico y productivo ${ }^{29}$. Para esto fue necesario generar las condiciones materiales y técnicas para las exhibiciones, dentro de un contexto en el que eran escasas las posibilidades de acceder a equipos de proyección de filmes de $16 \mathrm{~mm}$ en Chile. A diferencia de Estados Unidos, donde las iglesias, escuelas y bibliotecas normalmente contaban con este tipo de tecnología, la realidad latinoamericana obligó a la OCIAA a proporcionar dichos recursos o gestionarlos en conjunto con consulados y embajadas. El año en que finalizó la Segunda Guerra Mundial, la OCIAA ya había enviado alrededor de 300 equipos de proyección portátil y 69 camiones de proyección a toda América Latina. Sin embargo, eran las oficinas coordinadoras de cada país las que tenían que contratar técnicos para las proyecciones, conseguir recintos y espacios para mostrar las películas y definir el cronograma de exhibiciones ${ }^{30}$.

De acuerdo a las estadísticas de la OCIAA, el público alcanzó los 5 millones en determinados meses de la guerra, sumando a todos los países de la región ${ }^{31}$. La inversión de recursos para lograr este nivel de difusión fue impresionante y tendió a aumentar con el transcurrir del grave conflicto mundial, todo lo cual nos ayuda a ponderar la relevancia que Estados Unidos le dio a este gran proyecto de diplomacia cultural, el que no habría recibido tal cantidad de recursos, si no hubiese estado en directa sintonía con los grandes lineamientos diplomáticos del país.

En Chile organizaciones como la ANCC, el Coordination Committee for Chile (en adelante CCC), que era dirigido por el responsable de la Metals Reserve Company, Horace Graham, y la Embajada de Estados Unidos fueron importantes en la distribución de las películas gestionadas por la OCIAA y en el manejo de información relativa a la recepción de estas. La activa participación de funcionarios de la embajada es el fiel reflejo de una realidad: la diplomacia cultural no estaba escindida de los conductos y prácticas diplomáticas clásicas, sino plenamente integrada. A esto se agrega la colaboración indirecta y ocasional de instituciones chilenas que, sin proponérselo, también colaboraron en la difusión de la propaganda fílmica, como la Iglesia católica, que demandó exhibiciones especiales en las escuelas y organizaciones que dirigía, y Ferrocarriles del Estado, que garantizó pasajes liberados para los operadores de equipos de proyección que recorrieron el país durante la Segunda Guerra Mundial, aunque a cambio de exhibiciones especiales para sus funcionarios $^{32}$.

29 Véase al respecto lo ocurrido para el caso mexicano durante la Guerra Fría. Seth Fein, "Everyday Forms of Transnational Collaboration. U.S. Film Propaganda in Cold War Mexico", en Joseph, Salvatore y Legrand (editores), op. cit., 416-433.

30 El personal que trabajaba en Chile en 1944 estaba compuesto por: Eric Burnett, como director del programa fílmico en Chile; Víctor Martin, Armando Magré, Pedro Mena, Francisco Mena, Aquiles Vidal, Edwin Weasson, Alejandro García, Fernando Urzúa, Vladislav Sesnic, Adolfo Ugalde, Mario Cisternas, José Otero, Eulogio Velasco y Jorge Guerra, quienes proyectaban las películas a lo largo de todo el país; las secretarias Irene Herrmann y Dina Monsalve; y los mensajeros Alejandro Villalobos, Eduardo Vicuña, Luciano Magré y Segundo Valdés. Operating Budget Request, 23 de junio de 1944. NARA, RG 229, Caja 954, Carpeta, "Coordination Committee Motion Picture Activities, Chile".

31 Bender, op. cit., 230.

32 Memorando dirigido a Francis Alstock, Santiago, 2 de junio de 1943. NARA, RG 229, Caja 229, Carpeta "Films-Distribution". 
La colaboración de chilenos sentó las bases para la extensa difusión de propaganda fílmica, la que fue en aumento durante el gran conflicto mundial, alcanzando su peak en 1945. Las estadísticas indican que entre el 30 de octubre de 1942 y el 27 de noviembre de 1943 se dieron 447 exhibiciones en las ciudades de Santiago, Valparaíso, Concepción, Antofagasta, Coquimbo, Talca, Temuco y Valdivia, con una asistencia de 140.101 personas $^{33}$. El año 1945 resulta interesante de analizar por el contraste con lo acaecido 3 años antes. La ANCC contaba, a comienzos de ese año, con 23 proyectores de cine sonoro para operar en el país, con un stock de 1.725 películas en español, 42 mudas y 26 en inglés. En diciembre de 1945 ya tenía a su disposición 2.176 cintas de $16 \mathrm{~mm}$ en español, a lo que se agregaba el doble de películas mudas y 30 en inglés.

Más de 2 millones de asistentes fueron controlados en las 8.764 exhibiciones que se hicieron en el país durante los primeros 11 meses de 1945, una cifra impresionante si se considera que ya en 1942, con cifras menores, Chile se había convertido en el segundo país latinoamericano con más exhibiciones de propaganda en la región ${ }^{34}$

En 1943 Chile era el tercer país de América Latina con más proyectores de películas, detrás de México y Brasil solamente, y el segundo país con más recursos otorgados para las funciones de propaganda fílmica, después de Brasil ${ }^{35}$. ¿Por qué Chile fue uno de los lugares donde más se insistió en el uso del cine como medio de propaganda? La respuesta está en las propias palabras de Franklin D. Roosevelt, quien había declarado que la embajada en Chile era un puesto clave en la lucha contra el fascismo ${ }^{36}$. Esto se explica por la presencia y visibilidad de la colonia alemana, el notable aumento del intercambio comercial con Alemania en la década de 1930 y la prolongación de la política de neutralidad de Chile.

Hubo decenas de localidades donde las películas fueron proyectadas y llama la atención la gran cobertura geográfica. A las presentaciones en grandes ciudades, que abarcaron desde Iquique hasta Punta Arenas, se sumaron exhibiciones en lugares como El Tofo, Vicuña, Los Vilos, Peñablanca, Melipilla, Sewell, Cumpeo, Perquenco, Pillanlebún, Collico, Gorbea, Penco y Putaendo, por mencionar algunas de las decenas de localidades a las que llegó el programa propagandístico de la OCIAA. Esto fue posible, en parte, gracias a que las presentaciones no se realizaban siempre en salas convencionales, sino también al aire libre o con la ayuda de camiones dotados de equipos de proyección, uno de los cuales, donado por la empresa Coca Cola, operó en el país durante los últimos meses de

33 Carta de Charles Marshall a Nelson Rockefeller, 10 de enero de 1944. NARA, RG 229, Caja 229, Carpeta "Reports-Nontheatrical".

34 Reporte de W. E. Morrison, sin fecha. NARA, RG 229, Caja 229, Carpeta "Reports".

35 Memorando de la Motion Picture Division al Project Committee titulado "Increase in allotment of funds for the fiscal year 1942-1943, Non-Theatrical Film Distribution in the Other American Republics", 1943. NARA, RG 229, Caja 942, Carpeta "Non-Theatrical Film Distribution in Other American Republics".

36 Joaquín Fermandois, Mundo y fin de mundo. Chile en la política mundial 1900-2004, Santiago, Ediciones Universidad Católica de Chile, 2005, 159. 
1945 ${ }^{37}$. También se hicieron presentaciones en universidades, para Carabineros de Chile y en cárceles, como en el caso de Santiago, donde 150 prisioneros pudieron ver la película Der Fuhrer's Face y el documental South of the Border with Disney en $1944^{38}$.

\section{EXHIBICIÓN DE PELÍCULAS DE PROPAGANDA EN CINTAS \\ DE 16 MM EN CHILE.}

Febrero-diciembre de 1942

\begin{tabular}{|c|c|c|c|}
\hline 1942 & $\begin{array}{c}\text { Cantidad de pueblos y } \\
\text { ciudades donde se exhibieron }\end{array}$ & Cantidad de exhibiciones & Cantidad de asistentes \\
\hline Febrero & 1 & 22 & 7.015 \\
\hline Marzo & 3 & 48 & 18.279 \\
\hline Abril & 3 & 70 & 19.752 \\
\hline Mayo & 3 & 99 & 26.652 \\
\hline Junio & 2 & 85 & 21.655 \\
\hline Julio & 3 & 80 & 14.000 \\
\hline Agosto & 6 & 90 & 20.990 \\
\hline Septiembre & 9 & 90 & 27.525 \\
\hline Octubre & 12 & 116 & 45.810 \\
\hline Noviembre & 2 & 100 & 28.155 \\
\hline Diciembre & 5 & 236 & 48.368 \\
\hline Totales & 26 & 1.036 & 278.201 \\
\hline
\end{tabular}

Fuente: Informe elaborado por Andrés Magré Furet, 11 de enero de 1943. NARA, RG 229, Caja 229, Carpeta "Reports". El total correspondiente a la cantidad de ciudades y pueblos de exhibición da cuenta de que a lo largo de estos meses los filmes fueron exhibidos en 26 pueblos y ciudades distintas. Dicha cifra no es el resultado de la sumatoria de las cifras mensuales, porque hubo poblados en que hubo varias exhibiciones a lo largo de estos meses.

37 Reporte mensual de la Asociación Norteamericana de Cooperación en Chile a la Motion Picture Division de la OCIAA, Santiago, 27 de julio de 1945. NARA, RG 229, Caja 229, Carpeta "Reports".

38 Reporte de la División Regional de la OCIAA a Francis Alstock, 20 de abril de 1944. NARA, RG 229, Caja 229, Carpeta "Reports-June 1944". Mucha de la información contenida en esta carpeta corresponde a meses anteriores. 


\section{EXHIBICIÓN DE PELÍCULAS DE PROPAGANDA EN CINTAS DE 16 MM EN CHILE.}

Enero-noviembre de 1945

\begin{tabular}{|c|c|c|c|}
\hline 1945 & $\begin{array}{l}\text { Cantidad de pueblos y } \\
\text { ciudades donde se exhibieron }\end{array}$ & Cantidad de exhibiciones & Cantidad de asistentes \\
\hline Enero & 15 & 309 & 117.860 \\
\hline Febrero & 22 & 363 & 106.680 \\
\hline Marzo & 23 & 363 & 108.170 \\
\hline Abril & 29 & 580 & 142.688 \\
\hline Mayo & 48 & 753 & 210.515 \\
\hline Junio & 33 & 1.003 & 209.361 \\
\hline Julio & 46 & 1.109 & 214.681 \\
\hline Agosto & 39 & 1.305 & 282.678 \\
\hline Septiembre & 52 & 1.108 & 266.827 \\
\hline Octubre & 47 & 1.188 & 278.374 \\
\hline Noviembre & 23 & 683 & 160.394 \\
\hline Totales & 123 & 8.764 & 2.098 .228 \\
\hline
\end{tabular}

Fuente: Reportes mensuales enviados por la Asociación Norteamericana de Cooperación en Chile a la Motion Picture Division de la OCIAA. NARA, RG 229, Caja 229, Carpeta "Reports". El total correspondiente a la cantidad de ciudades y pueblos de exhibición da cuenta de que a lo largo de estos meses los filmes fueron exhibidos en 123 pueblos y ciudades distintas. Dicha cifra no es el resultado de la sumatoria de las cifras mensuales, porque hubo poblados en que hubo varias exhibiciones a lo largo de estos meses.

La profusa circulación del cine estuvo acompañada de otros medios propagandísticos; periódicos y revistas se transformaron en medios complementarios a través de los cuales se canalizaron mensajes favorables a Estados Unidos y su causa. Varias revistas chilenas acogieron sin mayor problema escritos y artículos preparados por autoridades de Estados Unidos en Chile. Un claro ejemplo es el caso del diario La Opinión y las revistas El Cabrito y Zig-Zag. Solo en mayo de 1944 esta última publicó 5 artículos entregados por el CCC, entre los que destacan: "La primera santa de los EE.UU." y "La epopeya del decimonono grupo de bombardeo del Ejército Norteamericano", los que fueron publicados a pocos días de haber sido recibidos. En ese mismo mes 133 historias relacionadas con la guerra fueron distribuidas por organismos de Estados Unidos en Chile, de las cuales 131 se publicaron en distintos medios. A lo anterior se suman 2.465 ejemplares de la revista de 
propaganda En Guardia que fueron distribuidos en mayo de 1944, además de 35 mil panfletos y 10 mil pósters con 9 diseños distintos, uno de los cuales decía "No dejemos al Eje meter las garras en las Américas"39.

\section{NÚMERO DE PÓSTERS DE PROPAGANDA DE ESTADOS UNIDOS RECIBIDOS Y REPARTIDOS EN CHILE EN MAYO DE $1944^{40}$}

\begin{tabular}{lcc}
\hline Pósters impresos en EE.UU. & Recibidos en Chile a la fecha & Repartidos, mayo de 1944 \\
\hline Guerra Ilustrada $N^{\mathrm{o}} 12$ & 3.518 & 2.083 \\
Guerra Ilustrada N ${ }^{\mathrm{O}} 13$ & 7.000 & 860 \\
Washington Portrait & 1.000 & 20 \\
Libres de temor & 5.000 & 4.490 \\
Unámonos contra la agresión & 3.000 & 1.920 \\
Ontiveros pósters & 1.500 & 640 \\
No dejemos al Eje meter las garras $\quad$ en las Américas & & 140 \\
Como un solo hombre & 2.500 & 100 \\
Cactus Póster & 2.600 & 100 \\
Totales & 1.200 & 10.353 \\
\hline
\end{tabular}

Fuente: Información contenida en diversos memorandos. NARA, RG 229, Caja 229, Carpeta "ReportsJune 1944".

\section{NÚMERO DE PANFLETOS DE PROPAGANDA DE ESTADOS UNIDOS RECIBIDOS Y REPARTIDOS EN CHILE EN MAYO DE 1944}

\begin{tabular}{lcc}
\hline Panfletos preparados en EE.UU. & Recibidos en Chile a la fecha & Repartidos, mayo de 1944 \\
\hline Marcha Fúnebre & 40.000 & 20.000 \\
War and the Americas & 10.000 & 180 \\
Transporte automotriz en las Américas & 4.500 & 1.500 \\
Hacia la victoria & 45.000 & 13.035 \\
Las Américas unidas & 1.000 & 140 \\
Spanish Speaking Americans in the War & 2.000 & 1.000 \\
Totales & 102.500 & 35.855 \\
\hline
\end{tabular}

Fuente: Información contenida en diversos memorandos. NARA, RG 229, Caja 229, Carpeta "ReportsJune 1944".

39 Información contenida en NARA, RG 229, Caja 229, Carpeta "Reports-June 1944".

40 También se prepararon, imprimieron y distribuyeron pósters en Chile. El mismo informe de 1944 da cuenta de la elaboración de 65.000 pósters en Chile, de los cuales 10.090 fueron repartidos en ese mismo mes. También se repartieron 390 mapas de guerra a la prensa, revistas y comentaristas de radio, entregados por los organismos de Estados Unidos activos en Chile. NARA, RG 229, Caja 229, Carpeta "Reports-June 1944". 


\section{PÓSTER DE PROPAGANDA PARA AMÉRICA LATINA}

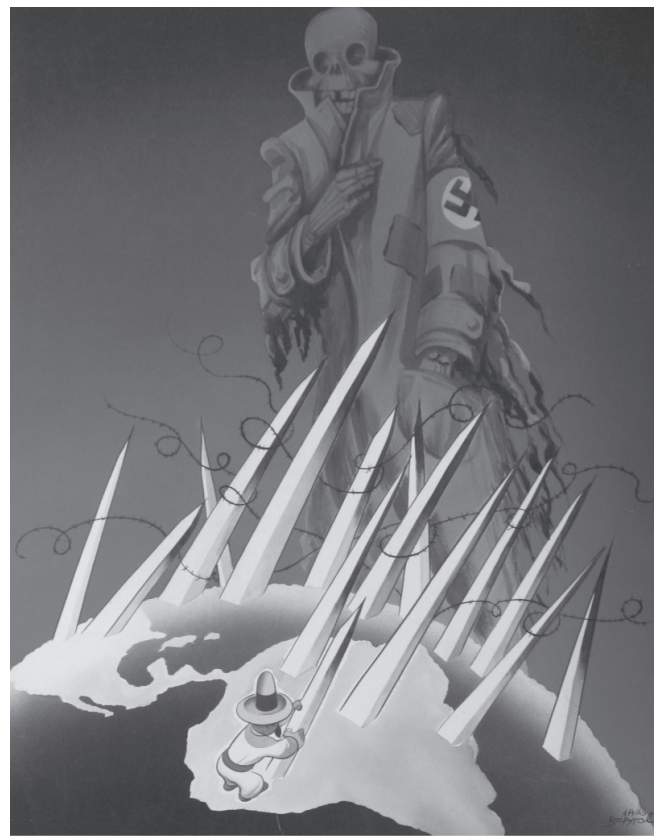

Fuente: NARA, RG 229, Prints and Artworks: Propaganda materials, 1941-1945, Caja 3, Carpeta 7.

Además de la impresión y distribución de pósters se realizaron otras acciones mediáticas, entre las cuales se puede mencionar el cambio de nombre de la escuela Salvador Sanfuentes por el de Estados Unidos, acto que estuvo acompañado por la exhibición de los filmes South of the Border with Disney y Victory Gardens, los que fueron "calurosamente recibidos y bienvenidos" 41 . La imaginación de los voluntarios del Cordination Committee for Chile llevó incluso a la realización de un programa de comedia radial titulado "Voluntarios del Sur", donde un roto chileno y un gaucho argentino narraban sus peripecias y aventuras luego de enrolarse en el "ejército del Tío Sam en el norte de África" ${ }^{2}$. El mismo Comité consiguió poner en la vitrina de una concurrida tienda del centro de Santiago una imagen de Arturo Prat junto a la de tres figuras representativas de Estados Unidos, un marino, un soldado y un aviador, todo lo cual fue decorado "artísticamente" y acompañado de un mensaje de saludo de las Fuerzas Armadas del país del norte a Chile con ocasión del 21 de mayo, en $1944^{43}$.

41 Reporte de la Asociación Norteamericana de Cooperación en Chile, sin fecha. NARA, RG 229, Caja, 229, Carpeta "Reports-January 1944".

42 "Weekly Report on Activities, Coordination Committee for Chile, Mayo 9-Mayo 15, 1943". NARA, RG 229, Caja 229, Carpeta "Reports".

43 "Weekly Report on Activities, Coordination Committee for Chile, Mayo 15-Mayo 21, 1944". NARA, RG 229, Caja 229, Carpeta "Reports-January 1944”. 
El nivel de la propaganda de Estados Unidos puede parecer excesivo, pero no hay que olvidar que el conflicto bélico no se resolvió sino hasta 1945 y que en contextos de guerra se tiende a exagerar la capacidad de acción de los enemigos, los que desarrollaron sus propias estrategias de propaganda. El chileno Andrés Magré, quien trabajaba estrechamente con las autoridades norteamericanas a cargo del programa fílmico, elaboró un informe privado en 1943, donde describía que:

"En Antofagasta, Tocopilla y especialmente en Iquique hay un ambiente anti-norteamericano tan marcado que no creo que lo haya en Valdivia, Osorno o Puerto Varas, con el agravante de que si en estas últimas ciudades hay ambiente nazi se debe a la presencia de una numerosa colonia alemana, en cambio en el Norte, son los chilenos mismos los que desacreditan a Estados Unidos".

Al mismo tiempo que destacaba esta lamentable situación, hacía un llamado directo a la acción a sus jefes directos:

"considero necesario que ustedes, mis jefes directos, usen su influencia y relaciones para ver modo de contrarrestar en alguna forma una campaña de murmuraciones que destruye todo lo que hacemos con prensa, radio y cinematografía a favor de un mayor acercamiento chileno-americano" 44 .

En las palabras de Magré había una cuota importante de exageración, pero este tipo de reportes mantenían vivo el interés por fortalecer los esfuerzos propagandísticos en el país, sobre todo si se considera que efectivamente hubo acciones de espionaje alemán en Chile y Argentina ${ }^{45}$. A esto se agrega una militancia considerable en el partido nazi chileno, que alcanzó poco más de mil personas en 1944, a lo que se sumaba la visibilidad de escuelas y organizaciones locales financiadas directamente por el Reich ${ }^{46}$. En todo caso, tal como ha señalado Joaquín Fermandois, hubo inventos "en serie" y el propio embajador de Estados Unidos en Chile, Claude Bowers, creía escasamente en el peligro, a pesar del "amplio círculo de creyentes o de tentados con esparcir este tipo de rumores" 47 . De hecho, pese a que en los reportes de esos años se hacía gran alarde de la difusión de películas provenientes de los países del Eje, el teatro Comedia era el único en Santiago donde se exhibían filmes "a favor" del Eje, los que provenían de Alemania, Italia y Japón. Un reporte de 1942 incluía una nota confidencial en la que se informaba que los distribuidores de películas de Estados Unidos en Chile se habían organizado, en octubre de 1941, para evitar que películas alemanas, japonesas e italianas fueran exhibidas en los cines donde ellos distribuían, lo que explica que solo en el Teatro Comedia, el que fue vetado por Hollywood, se pudieran ver aquellas provenientes del Eje. Así las posibilidades de exhibición se vieron drásticamente limitadas, lo

44 Andrés Magré F., "Informe privado a los señores W. E. Morrison y C. D. Marshall”. NARA, RG 229, Caja 229, Carpeta "Reports"."

45 Nocera, Chile y la Guerra..., op. cit., 172.

46 Nocera, "Ruptura con el eje...", op. cit., 402-403.

47 Fermandois, Mundo y fin de mundo, op. cit., 163. 
que explica que en 1941 se estrenaran en el país solo 12 películas alemanas, contra 320 de Estados Unidos ${ }^{48}$.

Es complejo, en términos metodológicos, medir el impacto de la propaganda fílmica, pero afortunadamente hubo un despliegue importante de información relativa a las exhibiciones en Chile, que en algo ayuda. Muchos chilenos participaron como informantes, enviando reportes que iban a parar a manos de funcionarios de la OCIAA en Estados Unidos. Gracias a esto podemos saber que el filme They Live Again contó con un extraordinario aplauso en la escuela $\mathrm{N}^{\circ} 7$ de Concepción, según lo informado por Aquiles Vidal, o que en la escuela San Antonio de La Serena los niños se quedaron con ganas de ver dibujos animados, como relató Adolfo Ugalde ${ }^{49}$. Por el contrario, la película Jeeps in War and Peace no gustó a 110 conscriptos que la vieron en Antofagasta ${ }^{50}$.

Los informes dan cuenta de la exhibición de títulos y temáticas muy variadas. Sin embargo, en su conjunto aportaban una representación atractiva de la modernidad y la eficiencia de Estados Unidos, de las principales características de su sociedad, de su geografía, de sus expresiones artísticas y deportivas, de sus instituciones educativas y de sus avances científicos y tecnológicos, sumando a ello filmes educacionales relativos a higiene y salud. También se exhibían películas sobre la guerra, el entrenamiento militar y una serie de aspectos relacionados con el gran conflicto bélico del momento, además de cintas que destacaban elementos ideológicos. Ejemplos representativos de los variados títulos exhibidos en Chile en 1945 son los siguientes: Alaska America's Frontier, Aluminum, Basketball, California Fashions, Cowboy, Democracy in Action, Fight Syphilis, How America Paints, Model Aviation, Soldiers of the Sky, This Amazing America y What is Electricity, por mencionar un grupo muy reducido, pero medianamente representativo. Otro caso es el de la película animada de Disney Der Fuhrer's Face, que obtuvo un Oscar en 1943 por su representación del Pato Donald viviendo los horrores del trabajo en la Alemania nazi. En la cinta, el Pato Donald, quien a cada instante debe levantar su mano derecha en señal de respeto a Hitler, termina despertando de lo que era simplemente una pesadilla y rindiendo honores a la Estatua de la Libertad. En 1945, este cortometraje fue exhibido en 16 escuelas, 5 hospitales e instituciones de caridad, un regimiento y una institución religiosa en Chile. A esto se suma una presentación en un centro cultural y otra en una organización obrera, además de 11 exhibiciones sin identificación específica en las estadísticas. En total fueron 36 funciones, que abarcaron a un público total de 6.055 personas en los primeros 11 meses de $1945^{51}$.

48 Reporte "Motion Pictures in Chile", preparado por Archibald Grey, Segundo Secretario, Consulado de Estados Unidos en Santiago, 26 de agosto de 1942. NARA, RG 229, Caja 229, Carpeta "Reports".

49 Entre quienes enviaban informes relativos a la recepción de películas figuran: Hugo Martin, Fernando Urzúa, Aquiles Vidal, Adolfo Ugalde, Francisco Mena, Edwin Weasson y Arnaldo Otero. Documento "Specific Comments From CC For Chile Re Content of Motion Picture Program". NARA, RG 229, Caja 229, Carpeta "Reports-June 1944".

50 Documento "Specific Comments From CC For Chile Re Content of Motion Picture Program". NARA, RG 229, Caja 229, Carpeta "Reports-June 1944", 2.

51 Reporte de la Asociación Norteamericana de Cooperación en Chile a la Motion Picture Division de la OCIAA, Santiago, 17 de diciembre de 1945. NARA, RG 229, Caja 229, Carpeta "Reports". 
Tanto las cifras de asistentes como la correspondencia enviada desde Chile dan cuenta de una general aceptación. Ya en 1942, el propio John Hay Whitney de la OCIAA felicitaba a Horace Graham, director del CCC, por el éxito alcanzado con las exhibiciones hechas en Chile ${ }^{52}$. Charles Marshall, secretario ejecutivo de dicha organización, informó en 1944 de que el programa de películas "es lejos el más efectivo" de la propaganda de Estados Unidos, destacando el hecho de que le había tocado observar una excelente reacción de los chilenos ante filmes que contaban con un $100 \%$ de contenido de guerra ${ }^{53}$. Un año antes había recomendado seguir la línea de películas como Steel, Alaska, Syphilis, This Amazing America y Power and the Americas. En forma especial sugería reforzar la exhibición de cintas como Steel, porque se hacía propaganda indirecta al mostrar el poderío industrial de Estados Unidos. Con este tipo de películas se evitaba que todo el repertorio estuviese explícitamente dedicado a Estados Unidos, lo que solía desencadenar críticas de las clases populares, a las que Marshall describió como "burlescas por naturaleza, desconfiadas y siempre listas para la crítica mordaz" 54 .

En una nota "Personal y Confidencial", el mismísimo J. Edgar Hoover, director del FBI, le informó a Nelson Rockefeller acerca de las "favorables reacciones [que] han sido detectadas en Chile respecto de los cortometrajes producidos por los estudios fílmicos de Estados Unidos". Hoover hizo referencia a fuentes confiables y puso como ejemplo en su informe la película Champions of the Army, la que había sido aplaudida por un buen lapso una vez concluida ${ }^{55}$.

Sin embargo, hubo casos puntuales de películas duramente criticadas. Tal como informó Lester Ziffren de la ANCC, las noticias exhibidas sobre el bombardeo de Monte Cassino habían generado reacciones entre los católicos en las salas de cine de Chile y agregó que chilenos pro aliados habían informado que en un teatro hubo aplausos luego de que se informara que los alemanes habían resistido a pesar del bombardeo ${ }^{56}$. Aunque en un tono menos dramático, se reportó que el filme documental "Esquiadores chilenos en Estados Unidos" había generado problemas en Valparaíso. El cónsul estadounidense en esa ciudad detalló las reacciones negativas del público, explicando que "el que se mostrase la bandera de Estados Unidos flameando sobre la chilena ha generado una desafortunada reacción". Continuaba agregando que "aparentemente el público, sin apreciar el hecho de que esta película fue filmada en Estados Unidos, donde la bandera de Estados Unidos debe tomar el lugar de honor, siente que esta forma de mostrar la bandera chilena es insultante". A pesar del problema, se encontró la solución y se ordenó a los operadores que

52 Carta de John Hay Whitney a Horace Graham, Washington, 17 de junio de 1942. NARA, RG 229, Caja 229, Carpeta "Films- Reaction".

53 Informe de Russell Pierce a Francis Alstock, 24 de abril de 1944. NARA, RG 229, Caja 229, Carpeta "Films- Reaction".

54 Carta de Charles Marshall a Nelson Rockefeller, Santiago, 9 de enero de 1943. NARA, RG 229, Caja 229, Carpeta "Films- Reaction".

55 Carta de J. Edgar Hoover del FBI a Nelson Rockefeller, Washington, 8 de agosto de 1942. NARA, RG 229, Caja 229, Carpeta "Films- Reaction".

56 Carta de Lester Ziffren a Nelson Rockefeller, Santiago, 29 de abril de 1944. NARA, RG 229, Caja 229, Carpeta "Films- Reaction". 
cortaran la escena de la secuencia en todas las copias que habían llegado al país. Quien escribió la carta con la información recibida desde Valparaíso concluía con sabiduría que "esta experiencia nos muestra claramente cuán cuidadosos debemos ser en la preparación de todos los filmes que se exhiban en las repúblicas americanas" 57 . Más allá de que encontrasen soluciones prácticas a problemas suscitados por algunas películas, muchos de los ejemplos recopilados demuestran la falta de habilidad de los policy-makers de Estados Unidos para poder controlar el cine como instrumento diplomático en términos absolutos.

Fuera de discusión está el éxito alcanzado en términos de transmisión de mensajes y los niveles de exhibición de los filmes de propaganda. Sin embargo, las lecturas de esos mensajes se dieron en contextos locales particulares, cuyas reacciones eran difíciles de anticipar por completo. En ese sentido se puede argumentar que hubo una cuota de ingenuidad al suponer que los filmes tendrían procesos de recepción unívocos. Más allá de que los personeros de la OCIAA, la MPSA y del Departamento de Estado planificaran al detalle cada una de sus producciones, una vez que la máquina proyectora hacía girar cada cinta, un nuevo conjunto de fuerzas era desencadenado, teniendo como protagonistas a millares de espectadores chilenos y no a los miles de estadounidenses que producían, comentaban y daban el visto bueno a los filmes en Washington, California o Nueva York.

\section{Proyectos fílmicos sobre ChILE}

Si bien es cierto hubo una enorme variedad de filmes de propaganda, ya sea directa o indirecta, fueron las pocas películas relacionadas directamente con Chile las que generaron más comentarios por parte de la opinión pública. Entre los proyectos hubo dos que alcanzaron mayor notoriedad: los documentales de Julien Bryan y los proyectos fílmicos de Walt Disney, a los que se puede agregar la película Chile: una nación valiente, mencionada al comienzo del artículo, que si bien nunca fue rodada, da pistas de los intereses y principios presentes en los procesos de producción de estos filmes.

Tres días después del ataque japonés a Pearl Harbor, en diciembre de 1941, John Hay Whitney, encargado de la División Fílmica de la OCIAA, le escribió a Horace Graham, responsable del CCC, que trabajaba bajo el alero de la Embajada de Estados Unidos en Santiago, informándole que en una reunión sostenida en Hollywood el 26 de noviembre, los representantes de todos los estudios se habían comprometido, por unanimidad, a producir películas comerciales de interés para América Latina, como parte del esfuerzo propagandístico. Le aseguró que estaba planeada la producción de varios filmes sobre Chile, por lo que le pidió su colaboración explícitamente, señalando que "para este fin necesitaremos ideas de su grupo acerca de aquellos elementos relativos a Chile que puedan 'venderse' mejor a

57 Carta de Charles Marshall a Nelson Rockefeller, Santiago, 27 de julio de 1943. NARA, RG 229, Caja 229, Carpeta "Films- Reaction". 
Estados Unidos" 58 . Es difícil saber si es que Horace Graham envió sugerencias al respecto, pero el hecho es que la MPSA evaluó la posibilidad de realizar distintas películas, como O’Higgins y Caleuche, además de Chile: una nación valiente. La MPSA terminó por abocarse a la tarea del denominado "Project Chile", el que comenzó a funcionar en 1942 y que debía tener como resultado el rodaje de la película Chile: una nación valiente.

La idea era producir un filme sobre Chile que "vendiera" una buena imagen del país en Estados Unidos, a la vez que influyera en la opinión pública respecto de la conveniencia de romper relaciones con el Eje. John C. Higgins, un canadiense de 34 años de edad que trabajaba en Hollywood, fue contratado para escribir el guión. Este señaló en abril de 1943, una vez que la sexta y última versión del guión estuvo terminada, que la película buscaba "explicar Chile y los chilenos a nuestra gente mostrando las diferencias en topografía, lenguaje y otros asuntos, pero destacando también las similitudes como su larga y dura lucha por la independencia, su avance en legislación social y sus libertades que son como las nuestras"59. Tal como se indicó, los protagonistas de la película iban a ser Juan Pérez y su esposa María Pérez, quienes fluctúan en el guión, temporalmente hablando, entre el presente de un Chile progresista y la guerra por la Independencia, en la que lucharon contra una España "totalitaria", elemento esencial del proyecto, en la medida que se buscaba que los espectadores chilenos establecieran una relación directa entre el nazismo y el régimen colonial español contra el que habían luchado. De hecho en el guión, que eleva como gran protagonista de la Independencia de Chile a fray Luis Beltrán, se hace mención explícita al capitán San Bruno como "el Heinrich Himmler de aquellos días". Así, Chile se convertía en un ejemplo de cómo históricamente y no solo durante la Segunda Guerra Mundial, se habían "sobrellevado dificultades en base al respeto del orden y las leyes", demostrando que los chilenos, tal como los estadounidenses, "han luchado siempre por su libertad cuando ha sido amenazada y así lo harán cada vez que sea necesario". Tal como señalaba el guión de la película, Chile era "una nación que le trae beneficios a su gente sin tener que recurrir a ninguno de los ismos: fascismo, nazismo, comunismo, y sin utilizar la violencia propia de esos "ismos" "60.

En lo que fue la tónica de las producciones hollywoodenses durante la guerra, se prestó especial atención a los detalles del guión. Este cuidado sería reconocido al año siguiente por la división fílmica de la OCIAA en su Report on the Latin American Film Project, al destacar que en los procesos de "adaptación de las películas se deben tomar en cuenta los principios generales que sustentan toda propaganda, adaptando las normas generales a la sicología y peculiaridades de América Latina como entidad y a la de cada país considerado individualmente".

58 Carta de John Hay Whitney a Horace Graham del Coordination Committee for Chile, 10 de diciembre de 1941. NARA, RG 229, Caja 229, Carpeta "Motion Pictures-Operating Films".

59 John C. Higgins, "Short Outline, Chile: Valian Nation", 15 de abril de 1943. MHL, Motion Picture Society for The Americas Records, Caja 4, Carpeta "Chile".

60 Guión final de la película Chile: Valiant Nation. MHL, Motion Picture Society for the Americas Records, Caja 8, Carpeta "Chile-Valiant Nation”, 34. 
Para ejemplificar, el reporte hacía referencia al arte de evitar conflictos, citando el caso del "sutil" cambio hecho a la película de propaganda This Amazing America, donde

"se hace referencia al episodio del ataque al Álamo durante la guerra de independencia de Texas. Este episodio, más allá de lo glorioso que pueda ser para la historia de Estados Unidos, produciría una impresión negativa entre los mexicanos. En nuestra versión alterada, el comentario sobre el Álamo fue reemplazado por una narración acerca del papel de los colonizadores españoles en la adopción del arte religioso barroco en América, todo lo cual no desentona con la secuencia de imágenes que se muestra en dicha sección de la película"61.

Algo similar ocurrió con el nombre de la película Imperio Americano, que cambió su nombre de distribución en América Latina por el de Mi hijo solo ${ }^{62}$.

La película Chile, una nación valiente no escapó al escrutinio de los críticos y es así como personal del Departamento de Estado no dudó en corregir "detalles" que se vislumbraban como fuente de conflicto. En una carta del 29 de enero de 1943, Laurence Duggan expresó sus objeciones al guión de John C. Higgins:

\begin{abstract}
"Páginas 2-3 y 4 . Tomando en cuenta que los chilenos son gente orgullosa y sensible y que sus sensibilidades son muy diferentes a las anglosajonas, ellos probablemente reclamarán con la secuencia que comienza con 'Tomemos la República de Chile', que continúa en la página 4 [porque suponía una intención intervencionista] Página 9. La afirmación de que todos en Chile poseen equipos de radio es incorrecta, y la aseveración de que la mayoría de las mujeres chilenas, incluso las de clase alta, fabrican su propia ropa, puede producir una reacción adversa entre los chilenos [...] Página 10. La referencia a que a los trabajadores chilenos sus sueldos apenas les alcanzan para vivir y que Chile es muy pobre para elevar el salario mínimo, debe ser eliminada [...] Página 34. La referencia a la sangre indígena debe ser evitada. Uno de los peores insultos en Chile es llamar a alguien "indio",63.
\end{abstract}

A pesar de todo el tiempo y esfuerzo empleado por el guionista y funcionarios de la MPSA, la OCIAA y el Departamento de Estado, la película nunca fue rodada. Esto porque el filme, más allá de intentar "vender" una imagen favorable de Chile en Estados Unidos, buscaba primordialmente influir en la decisión chilena de romper relaciones con el Eje, lo que Chile hizo en enero de 1943, justo antes de que comenzara el rodaje. Es así como la película pasó rápidamente al olvido, excepto para el guionista, quien meses más tarde se quejaría del no pago de sus honorarios y de que tendría que reformular sus proyectos, lo que lo llevaría muchos años más

61 Report on the Latin American Film Project, Motion Picture Division, OCIAA. NARA, RG 229, Caja 957, Carpeta "Renewal of Contracts for Processing Films".

62 "Weekly Report. Period Ending December 23, 1942", Motion Picture Society for the Americas. NARA, RG 229, Caja 961, Carpeta "Reports on the Motion Picture Society for the Americas".

63 Carta de Laurence Duggan del Departamento de Estado a Mr. Daniels, Mr. Bonsal y Mr. Stabler, 29 de enero de 1943. MHL, Motion Picture Society for the Americas Records, Caja 8, Carpeta "Chile-Valiant Nation". 
tarde a escribir guiones para películas fantásticas como Robinson Crusoe en Marte (1969) e Hijas de Satán (1972) ${ }^{64}$.

Los proyectos desarrollados por Julien Bryan fueron más exitosos y alcanzaron las pantallas chilenas y estadounidenses. Bryan fue uno de los numerosos documentalistas que trabajaron con la OCIAA, como Sullivan Richardson, Herbert Lanks, Willard Van Dyke y Frank Donovan. Sin embargo, fue él quien alcanzó mayor notoriedad, por cuanto produjo cerca del $30 \%$ del total de estos documentales, la mayoría dedicados a América Latina. Bryan era un viajero empedernido y aventurero, quien, cámara en mano, había registrado momentos históricos importantes; durante la Primera Guerra Mundial se desempeñó como chofer de ambulancia y tomó registros fotográficos de su experiencia; en la década de 1930 realizó documentales en la Unión Soviética y más tarde fue testigo privilegiado del bombardeo y la ocupación nazi de Varsovia. En forma independiente filmó el documental Americans All en 1940, el que fue usado por la OCIAA con mucho éxito en Estados Unidos para destacar las vinculaciones hemisféricas de ese país. El mismo Franklin D. Roosevelt elogió la película, lo que llevó a Nelson Rockefeller a establecer un contrato con Bryan para la realización de 21 documentales dedicados a explorar las particularidades de distintos países como Colombia, Venezuela, Argentina, Bolivia, Uruguay, Paraguay, Perú, México y Chile ${ }^{65}$.

Es importante hacer notar que 4 de los 21 documentales realizados por Julien Bryan estuvieron dedicados a Chile: Atacama Desert, Housing in Chile, Fundo in Chile y South Chile ${ }^{66}$. La serie buscaba fortalecer la idea de que Estados Unidos compartía elementos comunes con cada uno de los países de la región, por lo que su afinidad con América Latina en materia cultural y geográfica era lo que se destacaba en términos prioritarios. Esto es evidente en Fundo in Chile, donde se hace una comparación entre los valles centrales de Chile y California ${ }^{67}$. Bryan buscó realzar imágenes de Latinoamérica que dieran la idea de modernidad, de modo que los espectadores en Estados Unidos sintieran un cierto grado de familiaridad, a la vez que la sensación de influencia positiva en la zona. El propio documental Fundo in Chile contrasta a dos terratenientes chilenos que heredan tierras, uno de los cuales aumenta considerablemente su productividad gracias a los conocimientos de irrigación adquiridos en Iowa, mientras que el segundo no progresa al aferrarse a métodos tradicionales ${ }^{68}$. Este tipo de mensajes se veía reforzado con discursos sobre estabili-

64 Con respecto al no pago de honorarios a John Higgins, ver el memorando de Francis Alstock a John C. Higgins, 27 de octubre de 1943. NARA, RG 229, Caja 943, Carpeta "Production of War and Educational Motion Pictures".

65 Bender, op. cit., 213-214.

66 El documental South Chile se encuentra disponible en http://www.archive.org/details/ SouthChi1945. Fecha de consulta: 19 de abril de 2010.

67 La idea original de Bryan era hacer un documental sobre Chile central, sus paisajes y su gente, destacando las ciudades de Valparaíso y Santiago, además del entorno rural de las propiedades agrícolas. En definitiva optó por privilegiar el tema de la propiedad y productividad agrícola, a partir del cual se podían establecer mayores puntos de analogía entre Estados Unidos y Chile. Para una descripción del propio Bryan de su idea original, véase Carta de Julien Bryan a B. E. Cunningham, 25 de enero de 1944. NARA, RG 229, Caja 956, Carpeta "Project Reports".

68 Este documental se encuentra disponible en http://www.archive.org/details/FundoinC1949. Fecha de consulta: 19 de abril de 2010 . 
dad política y social, con pasajes que representan la existencia de servicios sociales asociados a vivienda, hospitales y educación, todos propios de sociedades con gobiernos progresistas como el de Estados Unidos en la época ${ }^{69}$. Esto último es más que evidente en Housing in Chile, filme en el que se narra la historia de una familia pobre que gracias a los programas de los gobiernos radicales adquiere una casa propia, alcanzando estándares de vida de clase media. El documental refuerza la idea de progreso, señalando que gracias a su nueva casa el futuro de la familia sería uno de "salud y felicidad". El pasaje final destacaba que "lentamente, pero de modo seguro todos están accediendo a mejores viviendas [...] todas diseñadas para los trabajadores de Chile"70.

La producción de estos filmes no escapó al escrutinio de las autoridades de la OCIAA, que procuraron hacer presentaciones a autoridades diplomáticas de los países incluidos en los documentales antes de su distribución, a lo que se sumaron las consultas a corporaciones empresariales de Estados Unidos cuando las circunstancias lo ameritaban ${ }^{71}$. Para el caso de Housing in Chile se hicieron una serie de observaciones luego de que se produjera la versión inicial. John Reinhardt de la división fílmica de la OCIAA sugirió cambios importantes, de modo de evitar la opinión negativa de los agentes del Departamento de Estado. Entre otras cosas tuvo reparos con la aparición de cuadros informativos sobre la mortalidad infantil en Chile y salarios comparados entre Chile y Estados Unidos, así como con diálogos relativos a la tuberculosis y escenas en donde se repetía "la abominable condición de pobreza" en que vivían muchos de los chilenos. Estos reparos, junto a la existencia de una narración que no daba pie a mucha esperanza, fueron considerados, de modo de generar una imagen positiva, evitando con eso el rechazo o la reafirmación de estereotipos negativos sobre Chile por parte de la sociedad de Estados Unidos $^{72}$.

En el caso de Atacama Desert, que originalmente se llamó North Chile, las autoridades de la Anaconda Copper Company objetaron dos frases de la voz en off del documental. Al describir las riquezas minerales del desierto de Atacama, el guión original señalaba:

"Una buena cantidad del total de ganancias de Chuqui y otras minas de cobre de propiedad de corporaciones norteamericanas van al gobierno de Chile, lo que ayuda a balancear considerablemente el presupuesto nacional. No muchas de estas ganancias terminan en manos de los mineros. Las condiciones de vida de ellos, a pesar de ser

69 Bender, op. cit., 220.

70 Este documental se encuentra disponible en http://www.archive.org/details/Housingi1943. Fecha de consulta: 19 de abril de 2010 .

71 Con respecto a la revisión de las autoridades bolivianas de los filmes documentales sobre ese país, véase Bender, op. cit., 217. Para el caso de la exhibición del filme documental Fundo in Chile en Canadá, las autoridades de la International Information Division le pidieron a Thomas Kilkpatrick de la OCIAA que solicitara permiso a las autoridades diplomáticas chilenas en ese país. Carta de Noel Macy a Thomas Kilkpatrick, 6 de febrero de 1945. NARA, RG 229, Caja 956, Carpeta "Project Reports".

72 Carta de John Reinhardt de la OCIAA a Julien Bryan, 29 de julio de 1943. NARA, RG 229, Caja 945, Carpeta "Ten Motion pictures on the other American Republics II". 
mejores que las de antiguos trabajadores mineros, no cubren las expectativas deseadas por ellos".

Las últimas dos oraciones fueron eliminadas del guión a petición de la Anaconda Copper Company, pero los costos de adaptación fueron traspasados por la OCIAA a la minera ${ }^{73}$.

\section{WALT DisNeY EN CHILE}

Walt Disney comenzó a producir filmes propagandísticos, en asociación con entidades gubernamentales de Estados Unidos y Canadá, desde antes de diciembre de 1941, fecha en que Estados Unidos entró directamente al conflicto de la Segunda Guerra Mundial. Entre 1941 y 1946 los estudios Disney produjeron 28 filmes educacionales, como se los denominaba, y 80 destinados al entrenamiento militar, además de 6 grandes producciones para la industria del entretenimiento. A esto hay que agregar la impresionante suma de 70 cortometrajes, de los cuales 6 fueron nominados al Oscar y dos lo obtuvieron (Der Fuhrer's Face y Lend a Paw). Cabe destacar que varias de las producciones destinadas a las salas de espectáculo fueron a la vez proyectos de propaganda producidos en conjunto con agencias gubernamentales, como es el caso de 3 de los 6 largometrajes estrenados durante la guerra: Victory Through Air Power, Saludos Amigos y Three Caballeros ${ }^{74}$. Llaman la atención las últimas dos películas, por cuanto sus temáticas, así como varios de sus personajes, son latinoamericanos, lo que revela el grado de importancia que el gobierno y la industria fílmica le asignaron a América Latina durante el prolongado conflicto, con la finalidad de fortalecer, a través del cine, una solidaridad hemisférica que resultaba esencial en el contexto de un enfrentamiento que adquirió ribetes globales.

Fue el propio Walt Disney quien viajó a América Latina en 1941, liderando un grupo de 18 personas, entre los que estaban el encargado de negocios John C. Rose, el director musical Charles Wolcott y varios dibujantes, productores y técnicos. El viaje del técnico en filmaciones John Walter Cutting a Brasil, que se inició el 6 de agosto de 1941 desde Miami, fue el inicio de un proyecto de gira que se prolongó hasta el miércoles 22 de octubre, con la llegada de los últimos profesionales de los estudios Disney de regreso a Estados Unidos. El equipo desarrolló actividades de producción en Brasil, Uruguay, Argentina, Chile, Bolivia, Perú, Ecuador, Colombia, Panamá, Guatemala y México, en lo que se constituyó como el proyecto emblemático de Walt Disney durante la Segunda Guerra Mundial ${ }^{75}$.

73 Bender, op. cit., 224.

74 Se pueden revisar los anexos A, B y C disponibles en Richard Shale, Donald Duck Joins Up: the Walt Disney Studio During War World II, Tesis doctoral, University of Michigan, Ann Harbor, 1976, 284-295.

75 Con respecto al itinerario, véase una descripción detallada de 39 páginas de las actividades diarias del grupo en "Report on the Walt Disney South American Field Survey", 22 de diciembre de 1941. NARA, RG 229, Caja 947, Carpeta "Report on The Walt Disney South American Field Survey". 


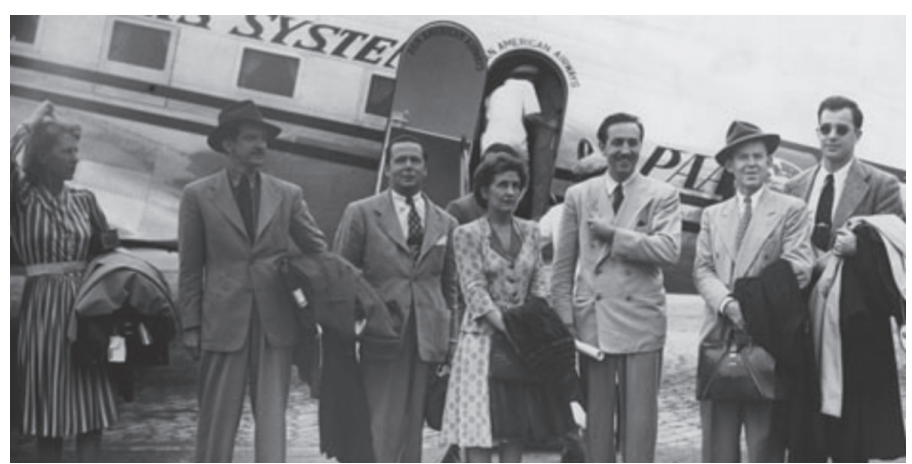

Disney y parte del grupo de acompañantes en su viaje por América Latina.

La visita de este equipo a Chile fue inaugurada por el encargado de negocios John C. Rose, quien fue el primero en instalarse en Santiago, ciudad a la que arribó el sábado 27 de septiembre, estableciendo el Hotel Carrera como centro de operaciones. "Llegó el 'papy' de Mickey”, informó de modo entusiasta la revista Ercilla en su portada, dos días después del esperado arribo de Walt Disney a Chile, el 29 de septiembre de $1941^{76}$. Ese día en conferencia de prensa en el salón Rojo del Hotel Carrera, Disney declaró que "mi viaje, repito una vez más, es de mera observación; lo que no impedirá que el más profundo y más simpático personaje creado bajo mi inspiración personal, esto es, Mickey Mouse, haga dentro de poco en el terreno fílmico y de la fantasía, un viaje por tierras sudamericanas"77. Reforzó la idea de que su viaje obedecía "a meras razones de estudio. No tengo misión oficial. Naturalmente, soy un gran amigo de Sudamérica y fui el primero en pensar dirigir especialmente la producción cinematográfica hacia los países latinoamericanos". Lo interesante es que Walt Disney quiso dejar muy claro que su visita no estaba vinculada al desarrollo de ningún tipo de propaganda, al señalar que "jamás he pretendido hacer propaganda política, religiosa, social en mis filmes. Ellos están dirigidos a las masas, por lo tanto, yo trato de cumplir los deseos del público"78. En los días en que estuvo en Chile nada hizo presagiar al público chileno que algún tipo de vinculación existía entre la diplomacia dirigida desde el Departamento de Estado y su proyecto. Por el contrario, una de las actividades que generó mayor atención y cobertura mediática tuvo que ver con su visita al fundo Santa Ana de Quilicura, de propiedad de José Ureta Morandé, en la laguna de Aculeo. Francisco Echeñique Searle y Luis Renard Valenzuela, jefe de Relaciones Culturales de la Casa Grace y Cía., organizaron esta jornada, que incluyó un rodeo y tuvo como protagonistas a los Huasos Quincheros, quienes interpretaron la cueca "Oro Purito" rodeados de parejas que bailaron junto al propio Disney, quien manto al hombro se animó a participar y bailar la cueca. Incluso Malú Gatica se hizo presente e interpretó algunas canciones, antes de que Walt Disney regresara a Santiago. Al día siguiente el Diario Ilustrado incluyó un

76 Ercilla, Santiago, 1 de octubre de 1941.

77 La Nación, Santiago, 30 de septiembre de 1941.

78 El Siglo, Santiago, 30 de septiembre de 1941. 
titular que decía: “Cabalgó con aperos chilenos, bailó cueca y tomó chicha, a todo campo, Walt Disney", agregando que había sido "un día magnífico en que se vivió plena vida de campo" y en donde el mismo Disney declaró que se había transformado en un "Perfect Chilean [sic] "Huaso"" 79. Por su parte, la revista Zig-Zag destacaría que "aquí, en tenida campesina, [Disney] comulga con la tierra chilena, apurando un vaso de sabrosa chicha" 80 .

Tal vez el hecho de que Estados Unidos no hubiera entrado formalmente al conflicto al momento de la visita de Walt Disney pueda explicar las reacciones poco suspicaces de la prensa chilena hacia su presencia. La revista Ecran indicaba en 1941, por ejemplo, que a pesar de que estallasen los "más terribles conflictos bélicos", Mickey Mouse siempre conservaría su "sonrisa contagiosa" y el Pato Donald su "atrevido optimismo", porque "nada les importa a ellos. Han sido creados para entretenernos". En definitiva, lo que Disney buscaba con su viaje a América Latina era, por tanto, un "enriquecimiento intelectual" 81 . El Diario Ilustrado destacó que la venida de Disney respondía a su necesidad de "empaparse en el ambiente sudamericano", para que pudiese "comprendernos más" antes de la creación de sus cartones ${ }^{82}$. En un artículo titulado "Lo característico de nuestro país estudiará Disney", el periódico le dio la bienvenida destacando que se cumplía un anhelo, porque "siempre abrigaron la esperanza de que algún día podrían aprovechar debidamente, en el medio de la animación, alguna parte, por lo menos, de la vasta riqueza que la América del Sur posee en literatura, música y costumbres, todo lo cual siempre les ha fascinado"83. Por su parte, el periódico El Siglo se limitó a señalar que "Disney realiza una gira de buena voluntad por los países americanos buscando temas y motivos para sus próximos screen cartoons, que versarán sobre temas latinoamericanos" 84 .

Las apreciaciones citadas eran radicalmente distintas a las que aparecían en la prensa norteamericana por aquellos años. Theodore Strauss, escribiendo para el New York Times, reconocería que el Pato Donald "se ha convertido en el propagandista número 1 del país", un personaje que "difícilmente tiene tiempo ahora para soñar con duendecillos, sátiras o flores con caras divertidas" 85 . Lo que estaba en la mente de Disney y de la OCIAA, dirigida por Nelson Rockefeller y dependiente del Departamento de Estado, era algo distinto. Tenía que ver con la utilización de los recursos de la entretención para fines diplomáticos, buscando el fortalecimiento de la solidaridad y entendimiento hemisférico, de forma tal que Estados Unidos estableciera un control importante de las acciones político-diplomáticas regionales, que se viera acompañada por una actitud positiva de los pueblos latinoamericanos hacia ellos. Tal como se señaló en la prensa norteamericana, la película Saludos

\footnotetext{
79 Diario Ilustrado, Santiago, 3 de octubre de 1941.

80 Zig-Zag, Santiago, 9 de octubre de 1941.

81 Ecran, Santiago, 30 de septiembre de 1941.

82 Diario Ilustrado, 29 de septiembre de 1941.

83 Idem, 28 de septiembre de 1941.

84 El Siglo, 29 de septiembre de 1941.

85 New York Times, New York, 7 de febrero de 1941.
} 
Amigos, que fue uno de los resultados de la gira por América Latina, se convirtió en "la primera película producida por Disney que se vincula al ámbito de las relaciones internacionales" 86 .

El proyecto que dio origen a Saludos Amigos y Tres Caballeros se había comenzado a discutir en junio de $1941^{87}$ y definió su objetivo tras el viaje de Disney a Latinoamérica en los siguientes términos:

"mientras el viaje de Disney constituyó un gesto sustancial de buena voluntad, una película basada en el viaje será el mayor gesto de adulación para el resto de las repúblicas americanas y pondrá énfasis en los lazos comunes que unen a la gente de las Américas. En un momento en que la solidaridad continental es de primerísima importancia, esta película proporcionará una demostración persuasiva de nuestros buenos deseos vistos en acción. Este tipo de factores unificadores, como los de esta película, son esenciales para la moral de los civiles tanto en nuestro país como en el resto de las Américas" $" 88$.

Este documento, en el que se definían los objetivos, recibió el visto bueno de parte de Laurence Duggan, asesor en relaciones políticas del Departamento de Estado, quien visó la propuesta de la OCIAA, organismo que a su vez se entendía directamente con Disney. La aprobación vino por intermedio de una carta enviada a John C. McClintock, "bajo el entendido de que la película, cuando se haya completado, debe ser revisada por representantes del Departamento de Estado para su aprobación final" 89 . Tras una serie de revisiones se llegó a un memorando de acuerdo el 2 de enero de 1942, en el que se establecieron las especificaciones contractuales entre "los Estados Unidos de América, mediante la Oficina del Coordinador de Asuntos Interamericanos (en adelante llamado 'Coordinador') y Walt Disney Productions Inc., Burbank California (en adelante llamado 'Disney')" ${ }^{90}$. El acuerdo, firmado por Nelson Rockefeller de la OCIAA y Roy Disney, hermano de Walt y vicepresidente de la compañía, establecía originalmente la producción de 12 cortometrajes como resultado del viaje de Disney a América Latina, los que debían ser entregados a más tardar el 30 de septiembre de 1942, debiendo tener las

86 Idem, 7 de febrero de 1943.

87 En ese entonces, la estimación de costos era de cerca de 60 mil dólares, cifra que fue posteriormente reducida. En aquel mes ya estaba instalada la idea de producir 12 cortometrajes sobre temas diversos, cuestión que variaría más adelante. Véase el documento "Walt Disney Field Survey and Short Subjects on the other American Republics", Project Authorization, 16 de junio de 1941. NARA, RG 229, Caja 216, Carpeta “Walt Disney Field. Survey \& Short Subjects”. E1 Departamento de Estado estuvo de acuerdo con los alcances generales del proyecto, lo que quedó ratificado con la aprobación de la idea a fines de junio de 1941. Carta de Laurence Duggan del Departamento de Estado a John McClintock, asistente ejecutivo de la OCIAA, 30 de junio de 1941. NARA, RG 229, Caja 216, Carpeta "Walt Disney Field. Survey \& Short Subjects".

88 "Walt Disney Sees South America", Project Authorization, 18 de diciembre de 1941. NARA, RG 229, Caja 216, Carpeta, "Walt Disney Sees South America".

89 Carta de Laurence Duggan a John C. McClintock, Washington, 31 de diciembre de 1941. NARA, RG 229, Caja 216, Carpeta "Walt Disney Sees South America".

90 Memorandum of Agreement, Contract No. OEMcr-108, 2 de enero de 1942. NARA, RG 229, Caja 216, Carpeta "Walt Disney Sees South America". 
cintas una extensión aproximada de 1.200 pies y cuyo título tentativo sería Walt Disney Sees South America. El acuerdo estipulaba la aparición en pantalla de personajes de Disney, así como la introducción de nuevos personajes sudamericanos, y que el costo de la producción, 45.000 dólares, sería pagado por el Departamento de Estado ${ }^{11}$. A la larga, el costo se elevó, alcanzando una cifra cercana a los 70.000 dólares, pero las ganancias por distribución y venta de entradas bordearon los 450.000 dólares ${ }^{92}$. Walt Disney declararía más tarde que "el gobierno nunca perdió un centavo en estas películas [Saludos Amigos y Tres Caballeros], nosotros pagamos por nuestro propio viaje y por la filmación también"93. Si bien Disney trabajó a costo muchos de los proyectos gubernamentales, lo cierto es que su vínculo con el gobierno norteamericano durante la guerra le permitió salir de una grave crisis económica y mantener el estudio a flote sin tener que recurrir a despidos $^{94}$. Eso explica que, tal como informara en 1942 el New York Times, el 80\% de la producción de Disney en esos momentos estuviese vinculada a contratos con el gobierno para el esfuerzo de guerra ${ }^{95}$.

El involucramiento de los estudios Disney con la causa de Estados Unidos era evidente en círculos internos y gubernamentales, así como en las pantallas de Estados Unidos y Canadá y la prensa norteamericana. Por el contrario, en América Latina se trató de oscurecer dicho vínculo, de forma de evitar una asociación entre Disney y el gobierno de Estados Unidos en la audiencia latinoamericana. Es por esto que una vez que el filme Saludos Amigos estuvo terminado, se tomaron una serie de decisiones, como la de que "la Oficina del Coordinador [de Asuntos Interamericanos] no aparecerá mencionada en la película"96.

Que los estudios Disney estuvieron muy interesados en participar en los esfuerzos propagandísticos durante la Segunda Guerra Mundial es innegable. Tras los acuerdos para la producción de cortometrajes animados derivados del viaje de Disney a Sudamérica, R. S. Carr, de los estudios Disney, produjo en febrero de 1942 un documento de 40 páginas, titulado "Ideas para un nuevo programa fílmico en Sudamérica", el que fue presentado a Luigi Luraschi, de la MPSA, quien lo calificó como "la aproximación más inteligente que he leído respecto del problema que tenemos en nuestras manos" $" 97$. El problema no era otro que la intensificación de la propaganda fílmica dirigida a Sudamérica, para lo cual Carr presentó 49 propuestas de propaganda directa e indirecta, varias de las cuales fueron finalmente producidas, como los filmes educacionales Defense Against Invasion, que busca-

91 Idem.

92 "Contract NDCar-110 with Walt Disney Productions Inc.", 1945. NARA, RG 229, Caja 960, Carpeta "Contracts and Suplements".

93 Citado en Bob Thomas, An American Original. Walt Disney, New York, Disney Editions, $1994,174$.

94 Thomas, op. cit., 172.

95 New York Times, 21 de junio de 1942.

96 Carta de Roy Disney a Phil Reisman de RKO Pictures, 29 de junio de 1942. NARA, RG 229, Caja 216, Carpeta "Disney in South America".

97 Anotación manuscrita de Luigi Luraschi hecha sobre el memorando enviado por David Hopkins a Luigi Luraschi, 12 de febrero de 1942. MHL, Motion Picture Society for the Americas, Caja 12, Carpeta "Ideas for more Walt Disney Films for South America". 
ba ser una "simple analogía entre los principios de la vacunación y los principios de la defensa contra la invasión"98, y otros filmes como The Hookworm, Tuberculosis y una serie titulada Human Body, todos los cuales ponían de relieve los daños provocados por enfermedades que podían ser contenidas, tal como las invasiones alemanas, italianas o japonesas.

En su informe, Carr destacaba que las películas de Disney para el Cono Sur debían ser "completamente diferentes respecto de los otros tipos de propaganda que están siendo enviadas a Sudamérica"99. Para eso se debía partir por "dar solo los fundamentos más simples", porque "si alguien quiere detalles, será mejor que se compre un libro"100. Agregaba en su informe que,

"la animación, siendo un medio mágico, tiene un profundo potencial para evocar sentimientos y sobrecogimiento. 'Ave María' en FANTASÍA fue solo el comienzo. Nosotros debemos aprovechar por completo esta cualidad en muchas de las películas propuestas, creando un sentimiento religioso profundo, asociándolo con ideales políticos"101.

En términos concretos, Carr propuso la creación de personificaciones que permitieran que factores abstractos o ideas cobraran vida en personajes. Para eso sugirió la idea de crear a "Hitlerito", quien podía ser "un monstruo de dos caras". Se podía al mismo tiempo caracterizar al "Rumor" como "un pequeño duende quien revolotea, depositando veneno en las orejas de la gente. El jabón, el sol y las vitaminas serán personajes simpáticos, mientras que los mosquitos, gusanos y moscas serán pequeños villanos fantásticos"102. Todo lo anterior requería la visualización simultánea de las palabras destacadas en las películas, porque "el valor propagandístico de las impresiones audiovisuales simultáneas es muy alto, debido a que estandariza las ideas al darle al espectador una imagen visual ya armada, antes de que se ponga a pensar y la interprete por sí mismo"103. Antes de incluir el listado y descripción de las 49 propuestas fílmicas, Carr destacaba también el papel de la música, debido a la "alta efectividad de jingles, versos y canciones que han sido valoradas por quienes moldean las mentes del público", lo que obligaba a no escoger "música apropiada" simplemente, sino a componer música pensada "conscientemente como parte de la propaganda", destacando la posibilidad de la creación de un "Himno Panamericano"104. En definitiva, muchas de estas ideas no solo fueron aplicadas a los filmes antes mencionados, sino también a aquellos de Disney bajo contrato con el gobierno, como Saludos Amigos y Tres Caballeros.

98 R. S. Carr, "Ideas for a new south American Film Program", febrero de 1942. MHL, Motion Picture Society for the Americas, Caja 12, Carpeta "Ideas for more Walt Disney Films for South America", 23.

99 Ibid., 1.

100 Ibid. 3.

101 Ibid., 3.

102 Ibid., 4.

103 Ibid., 5.

104 Ibid., 8. 
De regreso en Estados Unidos tras el periplo latinoamericano, el equipo creativo de Disney se lanzó a la tarea de producir los filmes, incorporando la mayor cantidad de elementos propagandísticos que permitieran contribuir a los objetivos trazados $^{105}$. En diciembre de 1941 todavía primaba la idea de producir una serie de 12 cortometrajes animados fragmentados. Aunque varios de los elementos que estarían presentes en la película Saludos Amigos'y Tres Caballeros ya estaban sobre la mesa en las discusiones a fines de 1941, habría cambios importantes. En ese instante se tenían en mente varios cortometrajes, muchos de los cuales serían luego fundidos.

Con respecto a los personajes, existía por entonces la idea de incluir a varias de las estrellas del mundo animado como el Pato Donald, Goofy (Tribilín), Mickey Mouse y Pluto, aunque en definitiva solo los dos primeros tendrían protagonismo en las dos grandes producciones que emergieron del proyecto. En cuanto a los nuevos personajes latinoamericanos que serían introducidos, llama la atención que originalmente se había pensado en dos personajes chilenos: un avión llamado Pedro y un pingüino bautizado como Pablo ${ }^{106}$. Solo el primero mantendría su nacionalidad, porque el segundo, que apareció en Tres Caballeros, se transformó en un personaje sin nombre "representativo" de la costa oeste sudamericana107.

En la medida en que se buscaba estrechar lazos de amistad y no generar ningún tipo de tensión con las representaciones, se optó por evitar al máximo interpretaciones raciales desfavorables para América Latina. El mejor ejemplo son las escenas de Brasil, en donde no aparecen negros en las variadas escenas de carnaval y de zamba, sino personajes blancos o mestizos. El mismo protagonista brasileño, Pepe Carioca, fue concebido como un personaje cuyos colores verde y amarillo simbolizaban la bandera de Brasil y evitaban la representación racial del pueblo brasileño. El mismo principio fue aplicado para el caso de Chile y Argentina. La estrategia rindió frutos en el país del norte, puesto que las reacciones en Estados Unidos fueron favorables una vez que se estrenó la película. En la crítica aparecida en el New York Times se comentó que, "como siempre en las películas del Sr. Disney, la calidad del humor es brillante y astuta, con toques caballerosos de sátira adornados con una entretención jovial"108. Por su parte, el Christian Science Monitor destacó que "la mezcla de animación y escenas de vida real anuncian la última novedad en la realización de películas" ${ }^{109}$. En el mismo periódico se señaló de forma entusiasta un mes más tarde que "en su conjunto la

$105 \mathrm{Si}$ bien es cierto el producto que le interesaba a la OCIAA eran las películas, los estudios Disney sacaron provecho de la experiencia publicando tiras cómicas o libros de viaje. Ejemplo de lo anterior es el libro de Walt Disney y H. Marion Palmer, Donald Duck Sees South America, Boston, D.C. Heath and Company, 1945. Para el caso puntual de Chile destaca la publicación de Walt Disney, Pedro. The Story of a Little Airplane, New York, Artists \& Writers Guild, Inc., 1943.

106 Memorando de John C. Rose a Francis Alstock, 3 de diciembre de 1941. NARA, RG 229, Caja 956, Carpeta "Foreign Versions of "Through the lands of the Americas with Disney"”.

107 Memorando Production of War and Educational Motion Pictures, sin fecha (el documento es posterior a julio de 1943). NARA, RG 229, Caja 943, Carpeta "Production of War and Educational Motion Pictures".

108 New York Times, 13 de febrero de 1943.

109 Christian Science Monitor, 2 de enero de 1943. 
película es una alegre contribución para el mejor entendimiento mutuo entre los dos continentes" 110 .

La película Saludos Amigos fue estrenada en Chile en septiembre de 1942, generando reacciones de regocijo de parte de un público que esperaba con ansias la exhibición del filme, tras el recordado paso de Disney por Chile el año anterior. Eso explica el titular de revista Ecran: "Walt Disney no se olvidó de Chile". La historia de Pedrito, el personaje chileno creado por Disney, fue el foco de atención de la crítica. En la película, Pedrito, llamado así en honor al presidente Pedro Aguirre Cerda, debe realizar un viaje allende los Andes ante la imposibilidad de sus debilitados padres de desplazarse a Mendoza en búsqueda de correspondencia. Tras cargar combustible, el pequeño avioncito cumple con el deber de cruzar la cordillera y recoger un morral con el correo postal. En su travesía de regreso logra vencer todas las adversidades climáticas posibles, burlando de paso las amenazas del temible Aconcagua. A pesar de que todos en Chile temían lo peor, es en medio de la neblina y de noche que Pedrito logra aterrizar, no sin dificultades, para entregar el bolso que contenía una tarjeta postal dirigida a Jorge Délano ${ }^{111}$.

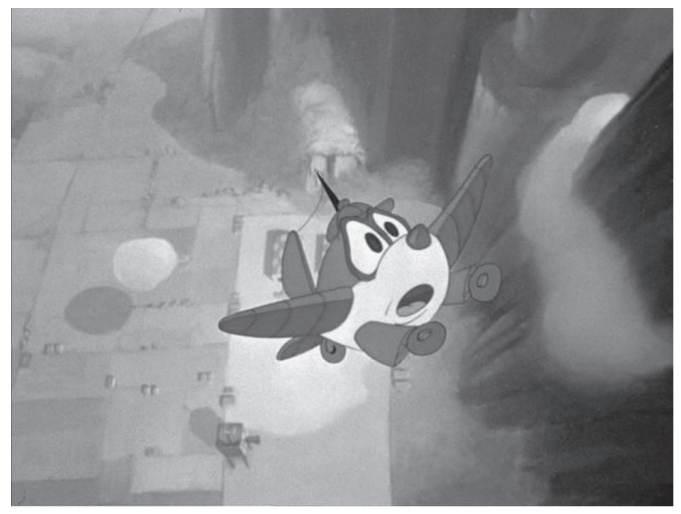

Pedrito, Saludos Amigos (1942)

La crítica fue variada y es así como, siguiendo la lógica del guión, el editor de revista Ecran se aventuró, entusiasmado, a plantear que en la película había un "un reconocimiento de lo que Chile ha hecho por la aviación comercial. Representa lo heroico, lo esforzado, lo que está más allá del cálculo y el gesto interesado"112. El comentario es el mejor ejemplo de lo señalado con anterioridad, en el sentido de que tras la exhibición de los filmes, el uso e interpretación de los mismos escapaba por completo del control de quienes habían producido las películas en Estados Unidos.

\footnotetext{
${ }^{110}$ Idem, 8 de febrero de 1943.

111 Jorge Délano estuvo colaborando indirectamente en el proyecto desde sus orígenes, lo que explica la referencia hecha a su persona por parte de Walt Disney.

112 Ecran, 22 de septiembre 1942.
} 
De las cuatro secciones de la película, la de Pedrito es la más débil. El personaje "chileno", a diferencia del brasileño José Carioca (que debutaba como personaje Disney en esta película) y de los consagrados Donald y Goofy, que visitan el lago Titicaca y Argentina respectivamente, es el menos cómico y atractivo, tal como fue resaltado en la misma revista Ecran por un crítico, quien señaló en su artículo que el paisaje chileno se representaba en la película "de un modo serio", a diferencia de lo ocurrido con los otros tres escenarios, presentados de modo más vívido y atractivo. Independiente de lo anterior, apuntó a modo de consuelo que, tal como dijo "Orson Welles, Chile es un país serio, al que es necesario estudiar antes de representar en las películas. Disney lo entendió también así, y no quiso caer en la sátira que, a lo mejor, no habría sido la fiel expresión de nuestras costumbres y de nuestros maravillosos paisajes". En la misma línea de los consuelos, terminaba por agradecer "el recuerdo que hace de nosotros", permitiéndole al pueblo chileno divertirse "con el guacamayo Pepe, con las correrías del gaucho Goofy y con ese panorama fantástico del Altiplano. Eso ya es suficiente" ${ }^{113}$. En otras palabras, se celebraba la posibilidad de reírse de otros países y de que se mantuviera una imagen sobria de Chile.

El contenido desilusionó a parte del público chileno, producto de que, tal como lo consignara El Mercurio, se trataba de una película "sobre temas sudamericanos" y no sobre Chile en particular ${ }^{114}$. Esto contrastaba con las expectativas de que Disney hiciera resaltar lo criollo y la identidad nacional, lo que había cobrado fuerza por el tipo de actividades desarrolladas por él en Aculeo. De hecho, al momento de la despedida de Disney de Santiago, el diario El Mercurio de esa ciudad había destacado que

"Disney y sus colaboradores han dejado en nuestro ambiente, el recuerdo cordial de su permanencia dispuesta a la comprensión de nuestras costumbres y modalidades para traducir en su magnífico arte, posteriormente, todo lo que ellos con su sensibilidad de artistas han podido captar consciente y cariñosamente" 115 .

Al momento de cubrir su visita a Chile en 1941, La Nación había indicado que Disney agradecería "toda información que se le proporcione, referente a obras artísticas o aspectos de la chilenidad, que sean aprovechables para la rama del cine que cultiva, y espera enriquecer su acervo con algunas creaciones de la cultura chilena"116.

\section{El Mercurio de Valparaíso había destacado por su parte que}

"los técnicos de Walt Disney, provistos de sus filmadoras portátiles, impresionaron en closed up los pasos de la cueca, el rasguear de las guitarras y el rápido movimiento de las manos en el clásico 'tamboreo'. Igualmente los vistosos trajes de huaso de 'Los Quincheros' fueron asimismo, tomados en todos sus detalles"117.

\footnotetext{
113 Idem.

114 El Mercurio, Santiago, 11 de septiembre de 1942.

115 Idem, 3 de octubre de 1941.

116 La Nación, 28 de septiembre de 1941.

117 El Mercurio de Valparaíso, Valparaíso, 4 de octubre de 1941.
} 
Todos estos comentarios revelan la existencia de ciertos intereses identitarios predominantes en el Chile de inicios de la década de 1940 y el alto grado de expectativas directamente relacionadas con esas particulares definiciones de una identidad esencialmente rural, al menos en el plano simbólico. Dichas nociones de identidad se vieron alimentadas por opiniones de integrantes del equipo como Charles Wolcott, director musical de las producciones Disney. En entrevista realizada por Pablo Garrido, Wolcott se refirió a sus planes en Chile, entre los que destacó la necesidad de

“conocer la música popular. Andamos en eso; buscamos todo aquello que nos sirva de referencia, de incentivo. Creo que la cueca chilena va a servirnos, pues sus características son asimilables al espíritu del dibujo animado. De modo que no se extrañen Uds., si un buen día escuchan sus propios ritmos haciendo danzar los extraños personajes de la fantasía de Mr. Disney"118.

El público chileno se quedó también con la impresión de que otros aspectos típicos del país se verían reflejados en las pantallas de cine de todo el mundo. Walt Disney fue entrevistado por Carlos Vattier de revista Hoy, y ante la pregunta "¿No se ha llevado de Chile ninguna historia fantástica para sus dibujos?”, Disney contestó "me han dado la leyenda del 'Caleuche', el buque fantasma de los mares del sur chileno, y me llevo también la curiosa fantasía de la 'Calchona', ese pájaro brujo y mal intencionado de los campos de Chile. Algún día los verán tomar vida en uno de mis filmes" ${ }^{119}$. Sin embargo, las expectativas acerca del supuesto rescate de la chilenidad por parte de Disney se diluyeron luego de la exhibición de una película que, a cambio de lo anterior, ofreció un guión en el que, tal como señaló un crítico de revista Hoy,

"Chile no aparece en fotografía. Sus impresiones las condensan los dibujantes en la mole andina. En Chile solo actúan aviones. Un papá-plano, una mamá-plano y 'Pedrito', un avioncito que cruza la cordillera como avión postal, que después de muchas peripecias, no todas graciosas, llega a su destino trayendo un saludo de Juan Carlos para Jorge Délano. El Aconcagua aparece como un gigante amenazador y terrible. Pero ni las ciudades ni los campos de Chile impresionaron ni a Walt Disney ni a los de su equipo" ${ }^{120}$.

La revista Ercilla resumió bien las sensaciones recogidas en Chile tras la exhibición de la película, al destacar, en noviembre de 1942, que

“cuando se estrenó 'Saludos', nuestros espectadores no disimularon cierto desencanto por el carácter episódico que le cabía a Chile en la sucesión de estampas sudamericanas. Brasil con su naturaleza en plena floración, Bolivia con el prodigio de sus indígenas y sus altos paisajes, Argentina con la pampa extendida como un océano de cuero, atrajeron la atención de Walt Disney y su equipo de dibujantes. Chile, en cambio, adquirió un

\footnotetext{
118 Las Últimas Noticias, Santiago, 2 de octubre de 1941.

119 Hoy, Santiago, 9 de octubre de 1941.

120 Idem, 10 de septiembre de 1942.
} 
carácter más internacional a los ojos del creador de los cartoons. Más que lo folclórico, se interesó Disney por grabar el empuje y el espíritu de sacrificio que encarna la cordillera de los Andes. De ahí que ni el huaso ni nuestro 'Verdejo' figuraran en la semblanza de Chile".

Las explicaciones para este tipo de expresiones críticas tienen que ver con que el Chile de la década de 1940 era esencialmente mesocrático y dado al culto de lo criollo y lo campesino, especialmente en el seno de una clase media consolidada en el poder político e influyente en lo cultural. Además, las reacciones y expectativas expresadas por muchos de los críticos con presencia en los medios de prensa reflejan el peso de una cultura política nacionalista, que por esos años tendía a promover los sentimientos e imágenes nacionales ${ }^{121}$. Muchos de ellos abrazaron imágenes de la vida rural que habían sido popularizadas y diseminadas por criollistas en las décadas anteriores, demostrando con ello el peso y trascendencia del esteticismo rural en la cultura nacional. Tal como ha señalado Patrick Barr-Melej, el criollismo había influido en la forma en que cuecas y rodeos se transformaron en prácticas culturales respetadas incluso en ámbitos urbanos ${ }^{122}$.

A pesar de todo, las esperanzas tras el estreno de Saludos Amigos no se habían perdido y en Ercilla se aguardaba con ansias el estreno de la segunda película del proyecto de Disney, en donde Chile sí que tendría un rol protagónico:

"Ahora, sabemos casi confidencialmente una noticia que ni aún en los Estados Unidos se conoce: Walt Disney prepara 'Sorpresas', segunda parte de 'Saludos', en donde a Chile le cabe el principal desempeño cromático. Ignoramos de qué modo nos ha captado Disney en este segundo trabajo suyo. No dudamos que, como siempre, será un acierto de agilidad y belleza"123.

La película "Sorpresas" se llamaba en ese momento Surprise Package en el círculo interno de los estudios Disney. Debido a que el título no permitía establecer una asociación directa con el mundo latinoamericano, Walt Disney propuso el título Let's go Latin, el que se mantuvo provisoriamente hasta el verano boreal de 1943, cuando se fijó como título Tres Caballeros, en alusión a Pepe Carioca, Pato Donald y el nuevo personaje mexicano Panchito Pistolas ${ }^{124}$. De los tres protagonistas ninguno fue chileno y el país estuvo lejos de alcanzar mayor notoriedad, excepto por la breve aparición del pingüino "Pablo" navegando sobre un trozo de hielo por la costa chilena, el que solo en memorandos internos de Disney fue concebido alguna vez como chileno, aunque ciertamente no en la película, donde terminó su viaje sudando en una hamaca entre palmeras en las islas Galápagos. Por el contrario, fue México el país que concitó mayor atención en el filme, lo que motivó

121 En relación al tema identitario ver Jorge Larraín, Identidad chilena, Santiago, Lom ediciones, 2001 y Sonia Montecino (comp.), Revisitando Chile: identidades, mitos e historias, Santiago, Cuadernos de Historia, Presidencia de la República, 2003.

122 Patrick Barr-Melej, Reforming Chile: Cultural Politics, Nationalism, and the Rise of the Middle Class, Chapel Hill, University of North Carolina Press, 2001.

123 Ercilla, 4 de noviembre de 1942.

124 Shale, op . cit., 212. Véase también el memorando de Nelson Rockefeller a Francis Alstock, 30 de octubre de 1944. NARA, RG 229, Caja 943, Carpeta "Records of the Department of Information". 
nuevos viajes de parte del equipo de Disney, esta vez a México, en diciembre de 1942 y en el otoño norteamericano de $1943^{125}$.

Tres Caballeros fue estrenada en Chile en mayo de 1945, casi tres años después de Saludos Amigos y a cuatro años de la visita de Disney a Chile. Las expectativas eran menores y la ansiedad había desaparecido, lo que explica que ante la ausencia de protagonismo chileno en la cinta, muchos de los comentarios de la crítica nacional hayan sido más bien técnicos. Es así como el Diario Ilustrado anunciaba el estreno de la película resaltando que se trataba de una "película que supera todo lo hecho hasta hoy en el cine, tanto en técnica como en arte"126. Por su parte la revista Ecran enfatizó las cualidades de la película, puntualizando que "el que se hayan enlazado por primera vez en una cinta de largo metraje los seres humanos, esto es, de carne y hueso, con las creaciones de Walt Disney, como ocurre en 'Los Tres Caballeros', pasará a la historia del cine como uno de los prodigios de este arte". Dora Luz y Carmen Molina de México fueron las actrices que junto a Aurora Miranda, hermana de Carmen, interactuaron en pantalla junto a los personajes animados de Disney. Agregaba la crítica de Ecran que se trataba de una película

"risueña, expresiva, salpicada de humor, desarrollada en forma fastuosa y hasta exuberante de fantasía, admirable desde el punto de vista técnico, sorprendente y única, la cinta de que hemos hablado es un hallazgo de la cámara móvil, y está llamada a enriquecer la sensibilidad de todos cuantos la contemplen"127.

A esto hay que sumar incluso los comentarios del periódico El Siglo, que, a propósito de la película, tendieron a magnificar la figura de Disney hasta un extremo inaudito:

"el gran artista que exaltó la ternura y nobles sentimientos, y puso en sus personajes la grandeza de alma y espíritu de lucha contra toda tiranía. El poeta del cine, Walt Disney, ha sido el Cervantes y el Shakespeare del celuloide, en punto a creación de personajes con profundo sentido y raíz humanas" 128 .

\section{CONCLUSIÓN}

Tras el estreno de Saludos Amigos en Estados Unidos, Bosley Crowther publicó un artículo en el New York Times donde planteó dudas acerca del cambio de percepción de los norteamericanos hacia Sudamérica, tras la proyección de este tipo de filmes. En su artículo "Howdy, Neighbors" [Hola Vecinos], Crowther cuestionó en 1943 los efectos de la política de buena voluntad del cine norteamericano de los últimos cuatro años, señalando que todo eso "ha sonado maravilloso, pero

125 Shale, op. cit., 213.

126 Diario Ilustrado, 20 de mayo de 1945.

127 Ecran, 22 de mayo de 1945.

128 El Siglo, 25 de mayo de 1945. 
cuando uno comienza a chequear evidencias se encuentra poco flotando alrededor. Al menos el asistente promedio al cine acá en Norteamérica, no ha visto mucho como para que sus corazones rebosen de cálidos sentimientos hacia nuestros vecinos del sur"129.

Más allá del efecto que puedan haber tenido ciertas películas en Estados Unidos, habiendo cumplido o no con la finalidad propagandística para las que fueron creadas, lo que es necesario resaltar es el enorme grado de aceptación del público latinoamericano en general y chileno en particular a las producciones fílmicas estadounidenses durante la guerra. Tal como se indicó, aspectos relacionados con la idiosincrasia de la sociedad chilena de la época generaron reacciones negativas hacia algunas cintas en particular, pero se trató de casos puntuales en donde Chile asumía una visibilidad individualizada y de filmes específicos sobre los que se habían generado enormes expectativas. Más importante que la opinión crítica respecto de películas puntuales, es destacar la masividad de la producción propagandística fílmica de Estados Unidos y los impresionantes niveles de difusión de esa producción en Chile. En este sentido es plausible argumentar que la asistencia reiterada de decenas de miles de chilenos a las funciones fílmicas organizadas por instituciones estadounidenses que operaban en Chile, generaron más de algún impacto favorable en la conciencia de miles de ciudadanos chilenos. Por lo demás, cuando hubo críticas hacia producciones determinadas, estas se focalizaron en las representaciones de Chile y su idiosincrasia y no de Estados Unidos y una causa bélica que fue compartida por la mayor parte de la sociedad chilena.

En una línea distinta, destaco por último el hecho de que este artículo demuestra que es posible incluir aspectos culturales dentro del estudio de las relaciones internacionales. Esto resulta evidente cuando estas se consideran en un sentido amplio, trascendiendo las vinculaciones entre organismos estatales y sus representantes. Sin embargo, el artículo también demuestra que la diplomacia cultural, muchas veces analizada en forma escindida de los conductos diplomáticos formales, ha sido parte integral de aquellos procedimientos diplomáticos que marcan las relaciones internacionales, especialmente desde que en el contexto de la configuración de sociedades de masas emergieron herramientas culturales como el cine, que brindaron enormes posibilidades para potenciar proyectos diplomáticos formales.

129 New York Times, 14 de febrero de 1943. 